\title{
A Physically Based Identification of Vertical Profiles of Reflectivity from Volume Scan Radar Data
}

\author{
PIERRE-EMMANUEL KIRSTETTER \\ School of Civil Engineering and Environmental Sciences, University of Oklahoma, NOAA/National Severe Storms Laboratory, \\ and Advanced Radar Research Center, National Weather Center, Norman, Oklahoma \\ HERVÉ ANDRIEU \\ L'Université Nantes Angers Le Mans, IFSTTAR Department GER and IRSTV-FR CNRS 2488, Bouguenais, France \\ BRICE BOUdEVILLAIN AND GUY DELRIEU \\ Laboratoire d'étude des Transferts en Hydrologie et Environnement, UMR 5564, UJF-Grenoble 1, CNRS, G-INP, IRD, \\ Grenoble, France
}

(Manuscript received 20 August 2012, in final form 20 February 2013)

\begin{abstract}
The vertical profile of reflectivity (VPR) must be identified to correct estimations of rainfall rates by radar for the nonuniform beam filling associated with the vertical variation of radar reflectivity. A method for identifying VPRs from volumetric radar data is presented that takes into account the radar sampling. Physically based constraints on the vertical structure of rainfall are introduced with simple VPR models within a rainfall classification procedure defining more homogeneous precipitation patterns. The model parameters are identified in the framework of an extended Kalman filter to ensure their temporal consistency. The method is assessed using the dataset from a volume-scanning strategy for radar quantitative precipitation estimation designed in 2002 for the Bollène radar (France). The physical consistency of the retrieved VPR is evaluated. Positive results are obtained insofar as the physically based identified VPR (i) presents physically consistent shapes and characteristics considering beam effects, (ii) shows improved robustness in the difficult radar measurement context of the Cévennes-Vivarais region, and (iii) provides consistent physical insight into the rain field.
\end{abstract}

\section{Introduction}

Reflectivity sampled aloft with ground radars is not always representative of the surface precipitation. Reflectivity varies with height because of various microphysical processes of melting, aggregation, collision, coalescence, evaporation, and breakup. In addition to the increase in beam elevation with distance, beam widening degrades the vertical sampling of the vertical structure of precipitation. This representativeness issue is increased in complex terrain where ground radars must sample precipitating systems at higher elevation angles. Vertical variations of reflectivity are one of the major sources of

Corresponding author address: Dr. Pierre-Emmanuel Kirstetter, National Weather Center, 120 David L. Boren Blvd., Rm. 4706, Norman, OK 73072-7303.

E-mail: pierre.kirstetter@noaa.gov error in the measurement of rainfall by weather radar; they potentially double the estimation error when not accounted for (Kitchen et al. 1994). The vertical variations of the radar reflectivity factor in the atmosphere are usually represented by the vertical profile of reflectivity (VPR), defined as the function describing the average variations over a given geographical domain with respect to a reference level. Correcting the error due to the VPR requires its determination, which allows reflectivity measured aloft to be projected onto the ground before it is converted into a rainfall rate (Delrieu et al. 2009). The VPR determination remains an open research subject despite the progress made during in recent decades. The methods proposed to identify the VPR can be classified into three categories: (i) the direct estimation of the VPR from measured volume reflectivity data (e.g., Germann and Joss 2002), (ii) the numerical identification of the VPR from the 
comparison of the radar data at different distances and altitudes to account for sampling effects (Andrieu and Creutin 1995; Andrieu et al. 1995; Vignal et al. 1999; Borga et al. 2000; Seo et al. 2000; Kirstetter et al. 2010), and (iii) the synthesis of the VPR with a few parameters (Kitchen et al. 1994; Tabary 2007). All these methods take advantage of volume radar data without which the VPR identification would not be possible. Yet the analysis of these radar data has also shown that VPRs display significant temporal and spatial variations. This explains part of the discrepancies noticed between radar and rain gauge at short time steps (Berne et al. 2004). VPR identification methods are not always able to cope with these fluctuations and might reach their limits despite the proposed improvements. For example, Kirstetter et al. (2010) showed the improvement gained by filtering the beam-sampling effects in the VPR estimation relative to an apparent VPR directly derived from measured reflectivity data and differently affected by the range influence. This method is derived from the VPR identification algorithm proposed by Vignal et al. (1999) based on inversion of reflectivity ratios computed at multiple elevation angles over the distance from the radar. However, a difficult radar measurement context (mountainous areas) shows the limits of the VPR identification used within the Traitements Régionalisés et Adaptatifs de Données Radar pour l'Hydrologie (TRADHy) software (Delrieu et al. 2009). A statistical control is applied on the variations of the VPR components about their a priori values. In case of strong or noisy fluctuations in the observations, the statistical control of the variations of the VPR components about their a priori values through a matrix of covariance (Vignal et al. 1999; Kirstetter et al. 2010) may be not robust enough to prevent getting physically unrealistic VPRs. Room for improvement remains regarding the correction of radar data for the VPR influence (Bellon et al. 2005, 2007).

Nevertheless, new progress on VPR identification can be expected by using the new observations provided by polarimetric radars for a better characterization of hydrometeors, especially in the melting zone (a key component of the VPR; e.g., Matrosov et al. 2007; Cao et al. 2012) and by modeling the vertical evolution of the physical properties of the hydrometeors (size distribution, shape, phase, electromagnetic properties, etc.). As an example Heyraud et al. (2008) suggested introducing a brightband bulk model into a data assimilation scheme. Modeling of the bright band has been addressed by various research studies, ranging from very comprehensive models (Willis and Heymsfield 1989; Klaassen 1988; Szyrmer and Zawadzki 1999; Fabry and Szyrmer 1999; Zawadzki et al. 2005) to simpler approaches (Hardaker et al. 1995; Boudevillain and Andrieu 2003). In sum, microphysical processes contributing to the VPR properties can help VPR identification.

Our goal is to propose VPR identification based on a physical parameterization of the VPR variations and on the modeling of the vertical variations of the equivalent reflectivity factor. The vertical model of the precipitating column requires a description of hydrometeor phase, size distribution, ice density, and morphology and melting-layer structure at each height level to properly simulate radar reflectivity. The radar-profiling algorithm is designed to capture the natural variability of these properties in as few parameters as possible. The VPR is identified from the comparison of the radar data at different distances and altitudes to account for sampling effects. A rain-typing algorithm is used for an a priori separation of convective and stratiform regions within the rain field (Delrieu et al. 2009). The VPR inference is time adjusted in the framework of an extended Kalman filter. This approach allows assimilating new radar observations to continuously update the VPR characteristics and ensures the temporal consistency of the parameters defining the VPR. The manuscript is organized as follows. Section 2 describes the model of the vertical variations of the equivalent reflectivity factor, inspired by Boudevillain and Andrieu (2003). Section 3 introduces the case study and details the data. Section 4 formulates the identification of the VPR parameters in the framework of a nonlinear Kalman filter. Section 5 presents the application of the VPR identification to the retained case study and discusses the obtained results. Section 6 closes the paper.

\section{Modeling the vertical variations of reflectivity}

This section presents a $1 \mathrm{D}$ model for the vertical variations of the equivalent reflectivity factor controlled by a limited number of parameters, allowing us to reproduce the main features of the VPR. The model simulates a static description of the atmospheric precipitation column along the line of Boudevillain and Andrieu (2003), Heyraud et al. (2008), and Ryzhkov et al. (2009). Kirstetter et al. (2012) proposed a VPR identification using a unique model with simple microphysics applied to all rain types. Here two distinct microphysics types are considered: convective and stratiform. This allows applying the VPR retrieval to rain domains defined by preliminary rain typing (convective, stratiform) as described in Delrieu et al. (2009) and Kirstetter et al. (2010).

Microphysical and dynamical processes drive the vertical variability of precipitation (Pruppacher and Klett 1998; Rogers and Yau 1989). These processes depend on the 
meteorological environment: temperature, pressure, and moisture. They control the vertical change of the particle size distribution (PSD), the phase (liquid and/or solid), the density, and the dielectric properties of particles. The equivalent radar reflectivity factor $Z_{e}$ at altitude $h$ is defined by

$$
Z_{e}(h)=\frac{\lambda^{4}}{\pi^{5}\left|K_{w}\right|^{2}} \int_{\Omega_{D}} \sigma[D, \lambda, m(h)] N(D, h) d D,
$$

where $\sigma\left(\mathrm{mm}^{2}\right)$ is the backscattering cross section of a hydrometeor that depends on the equivalent diameter $D$ and the complex refractive index $m(h)$; the refractive index depends on the phase of the hydrometeors and their temperature and on the radar wavelength $[\lambda(\mathrm{mm})]$. The term $N(D, h)\left(\mathrm{m}^{-1} \mathrm{~m}^{-3}\right)$ is the number of particles with diameters between $D$ and $D+d D(\mathrm{~m})$ per unit diameter range and per unit air volume at altitude $h(\mathrm{~m})$; $\Omega_{D}$ is the raindrop diameter range, assumed to be $\Omega_{D}=\left[0,+\infty\left[\right.\right.$. Finally, $\left|K_{w}\right|^{2}=\left(m_{w}^{2}-1\right) /\left(m_{w}^{2}+2\right) \approx 0.93$ is a constant depending on the refractive index of liquid water $m_{w}$, generally used in the expression of the radar constant for the interpretation of measured reflectivity (Doviak and Zrnic 1993). Equation (1) indicates that the equivalent radar reflectivity factor profile depends on (i) the phase of the hydrometeors, which drives their dielectric properties through a given scattering model (T matrix, Mie, Rayleigh); (ii) the PSD; (iii) the density and morphology of the frozen particles; and (iv), implicitly, the vertical profile of temperature that constrains, in particular, the altitude of the $0^{\circ}$ isotherm and the melting layer. The radar-profiling algorithm is designed to capture the natural variability of these properties in a reduced number of parameters (four) to derive the vertical variations of the equivalent reflectivity factor. The vertical resolution used is $50 \mathrm{~m}$, which is sufficient to resolve the microphysics calculations involved, especially in the melting layer. The next paragraphs address the parameterization of these variables.

\section{a. Main assumptions}

Three vertical layers are considered for describing the atmospheric column. The upper layer, denoted the solid layer, contains frozen particles. In the lowest layer, denoted the liquid layer, the precipitation particles are raindrops. The in-between layer is the melting layer in which particles are composed of a mixture of ice, air, and liquid water. These three layers are defined by their altitude boundaries. The top of the precipitating cloud, provided by the radar echo top, is denoted $h_{T}(\mathrm{~m})$. The altitude of the interface between solid and melting layers is denoted $h_{M}(\mathrm{~m}) ; h_{L}(\mathrm{~m})$ is the altitude of the interface between melting and liquid layers. A reference level close to the ground denoted $h_{0}(\mathrm{~m})$ is considered at the bottom of the liquid layer. The temperature is assumed to decrease with altitude following the saturated adiabat. A standard atmosphere is supposed with $100 \%$ relative humidity. In the solid and melting layers the particle size is defined by the equivalent melted spherical raindrop diameter.

\section{b. The liquid layer}

Hydrometeors are liquid drops whose mass density $\rho_{w}$ is constant $\left(\rho_{w}=1000 \mathrm{~kg} \mathrm{~m}^{-3}\right)$. Variability of the equivalent radar reflectivity factor is mainly driven by the PSD. The PSD serves to generate all bulk variables defining precipitation, such as water content, rainfall rate, or radar reflectivity. We use the gamma distribution (Uijlenhoet et al. 2003a,b; Yu et al. 2012, manuscript submitted to J. Appl. Meteor. Climatol.) that requires the total concentration $N_{t}\left(\mathrm{~m}^{-4}\right)$, a characteristic diameter $D_{0}(\mathrm{~m})$, and a dimensionless shape parameter $\mu$. In line with several authors (e.g., Testud et al. 2001), the characteristic diameter $D_{0}$ is taken as the mean volume diameter (ratio of the fourth moment to the third moment of the PSD). Since we will be using radar reflectivity measurements, it is convenient to parameterize the PSD as a function of $Z_{e}$ through the following expression (see the appendix for a full derivation):

$$
N\left(D, Z_{e}\right)=\frac{\lambda_{Z}^{\mu+7}}{\Gamma(\mu+7)} Z_{e}^{1-(\mu+7) \beta_{Z}} D^{\mu} \exp \left(-\frac{\lambda_{Z}}{Z_{e}^{\beta_{Z}}} D\right),
$$

where $\lambda_{Z}\left(\mathrm{~m}^{3 \beta_{Z}-1}\right)$ and $\beta_{Z}$ (dimensionless) are scaling distribution parameters (constants) and $\Gamma$ is the complete gamma function.

We assume that $Z_{e}$ varies linearly, according to $h$, between the value $Z_{0}$ at $h_{0}$ and a value $Z_{m}$ at the level $h_{L}$. The quantity $G_{l}=\left[\left(Z_{m}-Z_{0}\right) /\left(h_{L}-h_{0}\right)\right]$ is the slope of the VPR in the liquid layer. It is a parameter of the $1 D$ model. Consistent vertical variations of the PSD are obtained from Eq. (2) assuming that the PSD parameters $\lambda_{Z}, \beta_{Z}$, and $\mu$ are constant in the entire liquid layer. The PSD parameterization used herein is obtained from disdrometer measurements at ground level in the Cévennes region, France (Chapon et al. 2008; Yu et al. 2012, manuscript submitted to J. Appl. Meteor. Climatol.).

\section{c. The solid layer}

For both stratiform and convective types, the solid layer is defined between the level $h_{M}$ and the top level $h_{T}$, which are two parameters of the $1 \mathrm{D}$ model. In the solid layer, the hydrometeors are heterogeneous and described by a mixture of ice and air. Snowflakes are considered to 
occur in the stratiform regime and graupel/hail in the convective regime. From mass conservation, the size of frozen particles (snowflakes or graupel particles) $D_{s}$ is related to the size of the equivalent melted drop $D_{w}$ by

$$
D_{s}=D_{w}\left(\rho_{w} / \rho_{s}\right)^{1 / 3}
$$

where $\rho_{s}$ and $\rho_{w}$ are, respectively, the snow bulk density and the water density. The frozen particle density is described by a power-law relationship:

$$
\rho_{s}\left(D_{s}\right)=\gamma_{s} D_{s}^{-1} .
$$

The mass-diameter relationship of frozen hydrometeors is highly variable and has been the topic of many studies. The choice of the exponent value $(-1)$ is based on experimental studies (Mitchell et al. 1990), aircraft observations (Brown and Francis 1995; Heymsfield et al. 2002), and theoretical computations (Westbrook et al. 2004). The quantity $\gamma_{s}$ is a parameter of the $1 \mathrm{D}$ model. The density of particles is bounded to that of pure solid ice $\left(917 \mathrm{~kg} \mathrm{~m}^{-3}\right)$.

The density drives the composition of the particles through the respective air and ice volume fractions of the total particle volume. For the snowflake morphology in a stratiform situation, we use the model 5 from Fabry and Szyrmer (1999) where the particle is depicted as two parts: the core and the shell. The inner core is modeled as air inclusions in an ice matrix while the outer shell is described as ice inclusions inside an air matrix. The graupel/hail morphology for the convective situation is taken from Rasmussen and Heymsfield (1987) assuming homogeneous and spherical particles composed of air inclusions in an ice matrix. Fabry and Szyrmer (1999) detail the dielectric properties of the snowflakes. Ryzhkov et al. (2011) provide the equivalent for the graupel/hail.

The PSD of frozen hydrometeors is not yet well known and seems to be driven by temperature conditions (Fabry and Zawadzki 1995; Field et al. 2005). The concentration number $N_{t}$ and the diameter $D_{0}$ are assumed to increase linearly from the top level $h_{T}$ to the level $h_{M}$. This is supported by observations of midlatitude clouds (Heymsfield 2003, 2007; Field et al. 2007). The values for $N_{t}$ and $D_{0}$ at the level $h_{T}$ are inferred from the equivalent reflectivity factor fixed at $10 \mathrm{dBZ}$. The form of the VPR in the solid layer depends on the PSD defined at the top of the melting layer $h_{M}$ and on the mass-diameter relationship [Eq. (4)].

\section{d. The melting layer}

The melting layer is a transitional zone in which the backscattering properties of precipitation particles change rapidly. Its description has been addressed in depth (Rasmussen and Heymsfield 1987; Klaassen 1988; Szyrmer and Zawadzki 1999; Fabry and Szyrmer 1999; Zawadzki et al. 2005): a fast increase in dielectric constants of melting particles compared to those of ice particles in the beginning of the melting process leads to higher backscatter cross sections; as melting progresses, an increase in the fall velocity of melting particles diminishes their number concentrations. The possible enhancement of the measured reflectivity by the radar in stratiform rainfall, the bright band, occurs in this zone. Melting-layer models have two components: one describes the melting process in terms of microphysics variables and the other describes the scattering of melting particles. The melting-layer model for stratiform type is taken from Szyrmer and Zawadzki (1999) and Heyraud et al. (2008). The convective melting-layer model is taken from Rasmussen and Heymsfield (1987) and Ryzhkov et al. (2009). Both melting-layer models for snowflakes and graupel assume that collision, coalescence, and breakup processes have a small contribution to the total reflectivity and are neglected. One particle of size $D_{s}$ at the top of the melting layer $h_{T}$ melts into one raindrop of size $D_{w}$ below the melting layer. The flux particle number conservation is assumed preserved throughout the melting layer under a steady-state condition. Terminal fall velocities of raindrops and melting and frozen particles are used to derive the PSD of melting particles and the PSD of frozen particles at the level $h_{T}$ from the PSD of raindrops at the level $h_{L}$; this ensures continuity between the solid-melting-liquid layers. The distance fallen by a melting particle until it is completely turned to a raindrop is dependent on size. Two populations of particles contribute to the backscattered power: the melting particles and the raindrops (completely melted particles). The level $h_{L}$ is determined when raindrops contribute to $99 \%$ of the flux particle number.

The fall velocities of raindrops as a function of size were adopted from Sekhon and Srivastava (1971). For the stratiform rainfall type, the fall speed of melting snowflakes, the evolution of the melting fraction with height, and the particle size separating melting snowflakes and raindrops are taken from Heyraud et al. (2008) based on Mitra et al. (1990). The backscattering parameterization for melting snowflakes is adopted from Fabry and Szyrmer (1999); it is a function of the diameter, density, and melted fraction of the particle. For the convective type, the fall speed and melting of graupel/hail are taken from Rasmussen and Heymsfield (1987). Shedding of water from the surface of larger melting hail particles is not considered. The backscattering parameterization for melting graupel/hail is adopted from Ryzhkov et al. (2011). 
TABLE 1. Parameters for the framework.

\begin{tabular}{llll}
\hline \multicolumn{1}{c}{ Parameter } & & Model & Identification \\
\hline Echo top & $h_{T}$ & VPR & Kalman filter \\
Upper boundary of the melting layer & $h_{M}$ & VPR & Kalman filter \\
Density factor & $\gamma_{s}$ & VPR & Kalman filter \\
Slope of the profile in the liquid layer & $G_{l}$ & VPR & Kalman filter \\
Reflectivity at the reference level & $Z_{0}$ & VPR & Radar measurements \\
Radar wavelength & $\gamma$ & VPR & Fixed \\
Radar 3-dB beamwidth & $\theta_{0}$ & Radar sampling & Fixed \\
Radar elevation angles & - & Radar sampling & Fixed \\
Steady-state system error & $a, b$ & Kalman filter & Fixed \\
\hline
\end{tabular}

\section{e. Summary}

Practically, the vertical variations of the equivalent reflectivity factor are computed from altitudes $h_{T}, h_{M}$, density parameter $\gamma_{s}$, and reflectivities $Z_{0}$ at the level $h_{0}$ and $Z_{m}$ at an a priori level $h_{L}$ in three steps:

1) The PSD of raindrops is identified at the a priori level $h_{L}$ from the value $Z_{m}$ using Eq. (2).

2) The PSD of frozen particles is computed at the level $h_{M}$ from the PSD of raindrops using the flux particle number conservation and the particles terminal velocities (e.g., Heyraud et al. 2008). The reflectivity profile is computed in the melting layer. The level $h_{L}$ is updated. The slope $G_{l}$ is computed.

3) The reflectivity profile is computed in the liquid layer between $Z_{0}$ at the level $h_{0}$ and $Z_{m}$ at the level $h_{L}$. The vertical profiles of $N_{t}$ and $D_{0}$ are computed in the solid layer between the PSD at the level $h_{M}$ and the PSD at the level $h_{T}$. The reflectivity profile is computed in the solid layer.

The vertical variations of the equivalent reflectivity factor $Z_{e}$ with altitude can be represented from Eq. (1) using a model for the vertical variations of temperature, composition of hydrometeors, and PSD. These vertical variations of the equivalent reflectivity factor can finally be written $Z_{e}\left(Z_{0}, \varphi, h\right)$, where $\varphi=\left(G_{l}, h_{T}, h_{M}, \gamma_{s}\right)$ is the vector grouping the four parameters of the VPR model. Table 1 summarizes the parameters for the VPR identification framework. Reflectivity $Z_{0}$ is estimated from radar measurements; $\varphi$ is identified from apparent VPRs in the Kalman filter framework (section 4b).

The vertical profile of reflectivity, defined as the equivalent reflectivity factor $Z_{e}$ at altitude $h$ normalized by its value $Z_{0}$ at the reference level $h_{0}$ is expressed as

$$
z(\varphi, h)=Z_{e}\left(Z_{0}, \varphi, h\right) / Z_{0} .
$$

One of the parameters is the gradient of the equivalent radar reflectivity factor in the liquid layer; two of them concern altitude levels and the last is related to the density of frozen particles. Figure 1 illustrates the various shapes of VPRs, which can be derived from the proposed models for convective and stratiform rainfall. Three types of variation are considered: characteristic altitudes, reflectivity gradient in the liquid layer, and the density factor in the upper layers. Both melting-layer models relate $Z_{0}, G_{l}$, and $\gamma_{s}$ to the thickness of the melting layer. The reflectivity value $Z_{m}$ at the level $h_{L}$ is linked to the melting layer as shown on Fig. 1a: the greater the reflectivity $Z_{m}$ is, the greater are the peak-torain reflectivity and the melting-layer thickness as mentioned by Fabry and Zawadzki (1995) and Heyraud et al. (2008). A higher density increases the terminal velocity of the particles and consequently, the meltinglayer thickness. As can be seen in Fig. 1b, the increase in the $\gamma_{s}$ parameter leads to a smaller peak-to-rain reflectivity because of the density effect (Zawadzki et al. 2005 for the stratiform case). Table 2 gives variation intervals of these parameters according to physical considerations. The top of the precipitation is limited to $15 \mathrm{~km}$, which can be reached in case of strong convective updrafts. The $\gamma_{s}$ values are bounded between 1 and 400 so that the average bulk density of frozen particles $\bar{\rho}_{s}$ (density weighted by volume) spans various frozen particle types like snow $\left(\bar{\rho}_{s}\right.$ from 10 to $350 \mathrm{~kg} \mathrm{~m}^{-3}$; i.e., $\gamma_{s}$ from 1 to 15$)$, graupel ( $\bar{\rho}_{s}$ from 50 to $900 \mathrm{~kg} \mathrm{~m}^{-3}$; i.e., $\gamma_{s}$ from 5 to 400$)$, and hail $\left(\bar{\rho}_{s}>800 \mathrm{~kg} \mathrm{~m}^{-3}\right.$; i.e., $\left.\gamma_{s}>90\right)$. The conditions of the two models for determining the stratiform and convective VPRs will be presented in section 4 .

\section{Case study}

A detailed description of the Bollène 2002 experiment can be found in Delrieu et al. (2009). This experiment was designed to evaluate the benefits of a radar volumescanning strategy for radar quantitative precipitation estimation (QPE) in mountainous regions and served to develop the TRADHy system. During the experiment, the Bollène radar performed three plan position indicators 

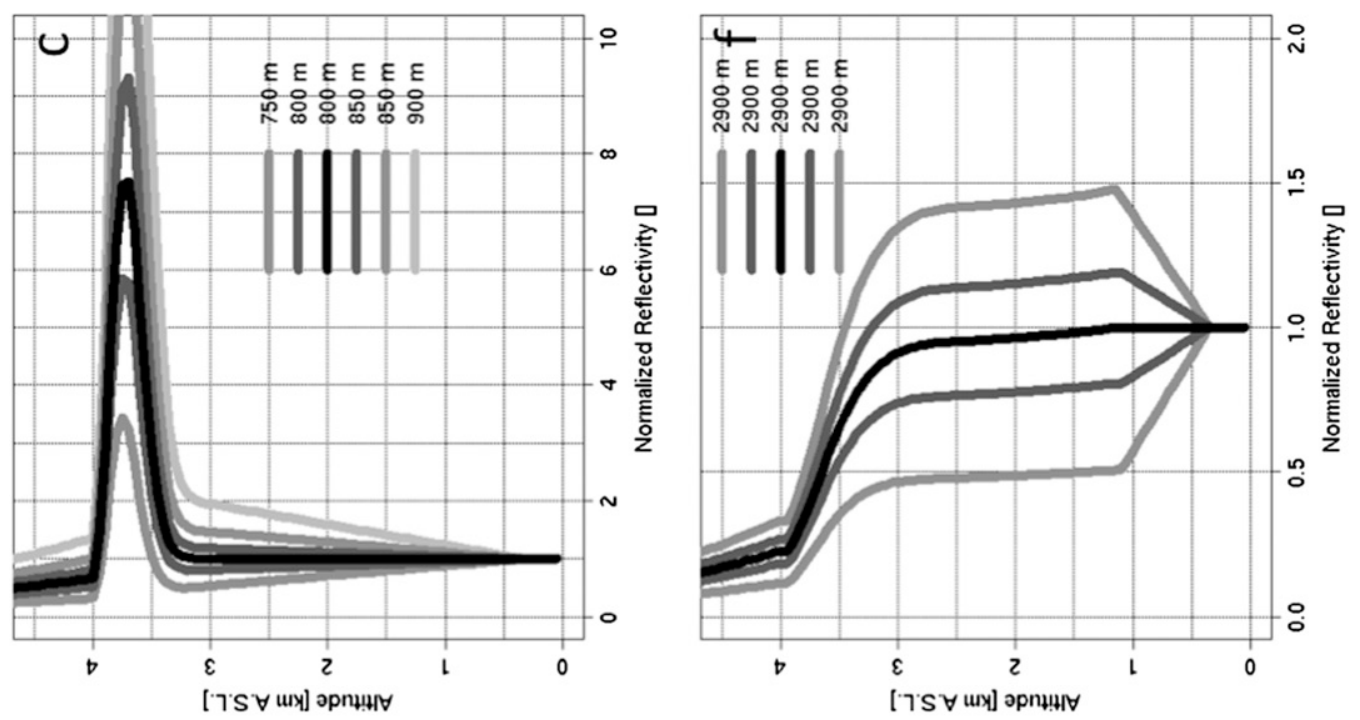

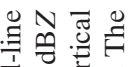

言会高

है

$\checkmark$ 을

इ司苍荠

를 己

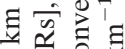

곡 8

틍

氖氜

है

胥。ं

कृ సิ

는

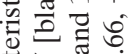

ป ํํํ
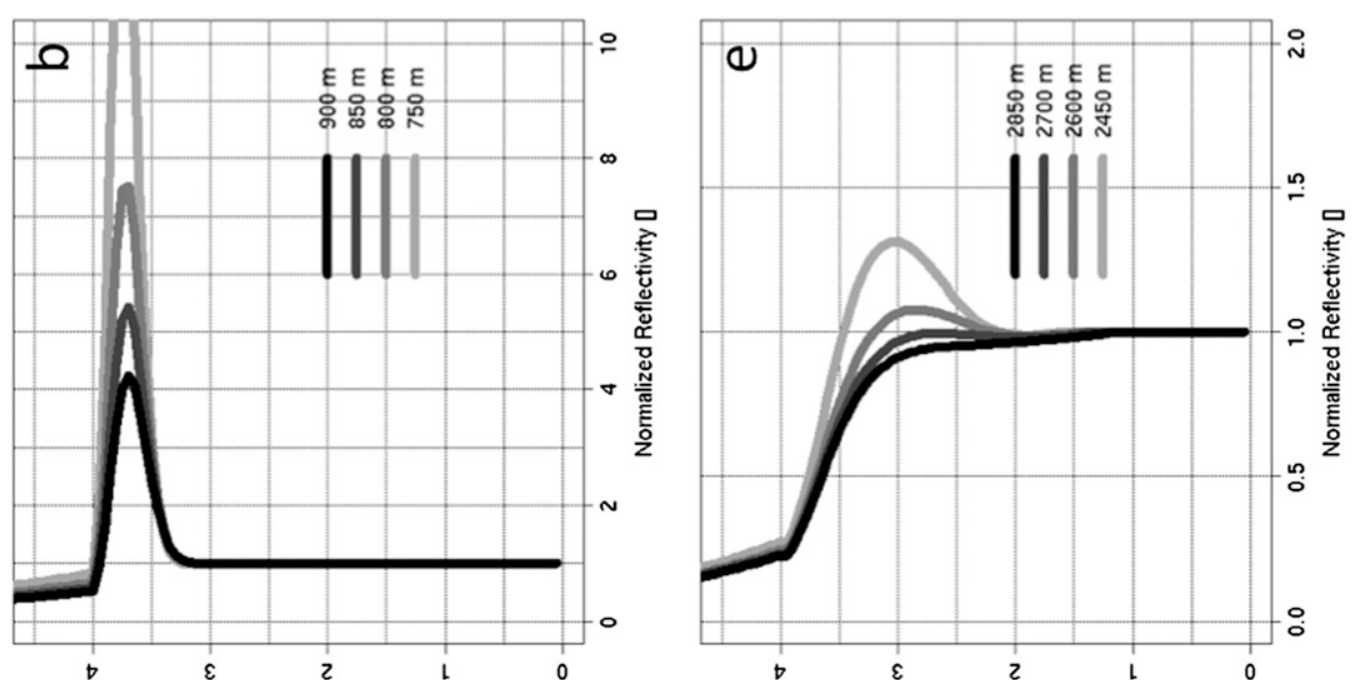

워월

क्जि

$\because$ 도

워묘

它的戛

술 娄

$>>n$

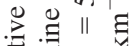

记

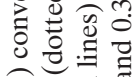

(ี

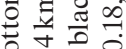

¿ 11 .

평

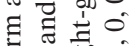

ฮํ.

氜 음

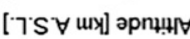

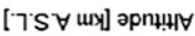

क 115
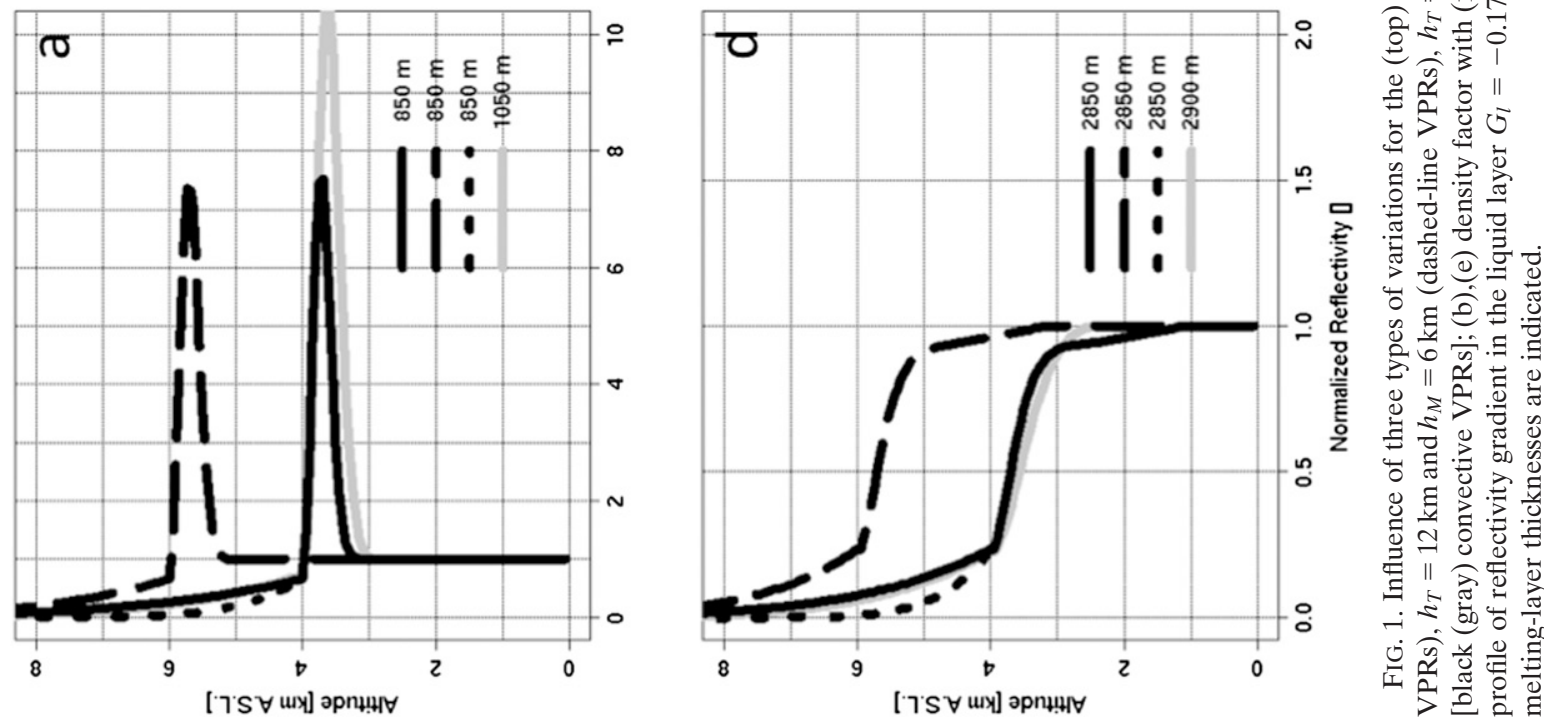
TABLE 2. Values of the input parameters for the VPR model.

\begin{tabular}{lllr}
\hline \multicolumn{1}{c}{ Input parameter } & & Units & Domain \\
\hline Echo top & $h_{T}$ & $\mathrm{~km}$ & $0-15$ \\
Upper boundary of the melting layer & $h_{M}$ & $\mathrm{~km}$ & $0-10$ \\
Density factor & $\gamma_{s}$ & - & $0-400$ \\
Slope of the profile in the liquid layer & $G_{l}$ & $\mathrm{~km}^{-1}$ & $-0.5-0.5$ \\
\hline
\end{tabular}

(PPIs) at angles of $0.8^{\circ}, 1.2^{\circ}$, and $1.8^{\circ}$ at an antenna rotation rate of $10^{\circ} \mathrm{s}^{-1}$, complemented by two sets of five PPIs, alternated every $5 \mathrm{~min}$ at an antenna rotation rate of $15^{\circ} \mathrm{s}^{-1}$, allowing an enhanced sampling of the atmosphere at 10-min intervals (Delrieu et al. 2009). The 3-dB radar beamwidth is $1.28^{\circ}$ and the radar range is $120 \mathrm{~km}$. The radar reflectivity data are available for each $1 \times 1 \mathrm{~km}^{2}$ Cartesian mesh of each PPI.

During the experiment, an exceptional mesoscale convective system (MCS) was sampled on 8-9 September 2002 (Delrieu et al. 2005; Bonnifait et al. 2009). It was a particularly catastrophic event in which total rain amounts reached $700 \mathrm{~mm}$ in $28 \mathrm{~h}$. Delrieu et al. (2005) divided the event into three phases: an initial period (0800-2200 UTC 8 September) during which the MCS developed and became stationary in the northwest region of the city of Nîmes; a second phase (from 2200 UTC 8 September to 0400 UTC 9 September) in which the mature MCS moved and stayed at the limit of the Cévennes Mountain Ridge; and a final phase (04001200 UTC 9 September) in which a cold front swept the MCS out of the region. To illustrate the application conditions of the VPR identification, we will be using the radar data collected during this event characterized by a marked spatial and temporal heterogeneity. Figure 2 shows results of the rain separation technique from TRADHy as well as the variability in 3D measured reflectivity for the example of 0200 UTC 9 September 2002. The graphs display different quantiles of the probability density functions (PDF) for reflectivity measured in stratiform and convective zones as a function of altitude within $70 \mathrm{~km}$ of the radar [see Delrieu et al. (2009) for more details]. The rain separation leads to distinct median profiles, for example, median values of 47 and $33 \mathrm{dBZ}$ at $h=2 \mathrm{~km}$ for the convective and stratiform PDF, respectively.

Figure 3 shows the convective and stratiform VPRs identified within the TRADHy software at 0200 UTC 9 September 2002. The impact of the radar beam effects is mitigated. Simulated VPRs from the 1D model are also shown to illustrate the ability of the physically based model to reproduce the features of typed VPRs. The reference level $h_{0}$ is $1000 \mathrm{~m}$. The $Z_{0}$ values are extracted from Fig. 2 and are equal to $1000 \mathrm{~mm}^{6} \mathrm{~m}^{-3}(30 \mathrm{~dB} Z)$ for the stratiform case and $50118 \mathrm{~mm}^{6} \mathrm{~m}^{-3}(47 \mathrm{dBZ})$ for the convective case for the considered time step. Table 3 lists the parameter values serving to define the modeled VPRs. It also shows the melting-layer thicknesses and the average bulk density of frozen particles $\bar{\rho}_{s}$. The features of the modeled VPR are cruder than the identified VPR within the TRADHy software. Yet the TRADHy stratiform VPR presents a thicker bright band $(2 \mathrm{~km})$ than the modeled VPR. To reproduce the peak-to-rain reflectivity, an unusually high value for snowflakes density $\gamma_{s}$ is needed. A more physical value for $\gamma_{s}$ would have resulted in a greater peak-to-rain reflectivity. Kirstetter et al. (2010) showed that the beam-smoothing effects decrease the peak-to-rain reflectivity and increase the thickness of the bright band for the apparent stratiform VPR. Even if it has been mitigated in the TRADhy software so that the identified VPR presents physically more consistent shapes and better characteristics than the apparent VPR, correction for residual beam effects still may be needed using physically based constraints. The modeled convective VPR does not present oscillations of the convective VPR in the altitude interval (1-3.5) $\mathrm{km}$, which is attributed to artifacts of the inversion technique used in TRADHy (cf. Kirstetter et al. 2010).

\section{The VPR identification method}

The objective is to determine the parameter values $\varphi$ and their time variations that will allow reconstitution of the best vertical variations in reflectivity captured by the radar observations during a rain event. The first paragraph presents the data for the VPR identification and the second one addresses the relationship between the data and the parameters of the VPR models. The VPR identification is performed in the framework of an extended Kalman filter (EKF) described in the third paragraph, and the fourth paragraph discusses the application of this technique to the estimation of the VPR parameters. In the following, though the data are time dependent, the time $t$ is not explicitly mentioned for the sake of keeping the formulations concise.

\section{a. The data: Rain-typed apparent VPRs}

The radar provides the vertical variations of the equivalent reflectivity factor discretized according to the elevation angles and smoothed according to the beam characteristics. For any rainy pixel in the radar detection domain these observations constitute a vector of $n$ components denoted $\mathbf{Z}_{\mathrm{em}}$, where $n$ is the number of elevation angles. We consider two subsets according to the rain separation typing-convective and stratiform (Delrieu et al. 2009). The VPR to be identified from each subset describes the average vertical variations of the equivalent reflectivity factor. The vectors $\mathbf{Z}_{\mathrm{em}}$ classified by rain type are assumed to be homogeneous and to display the same VPR. 

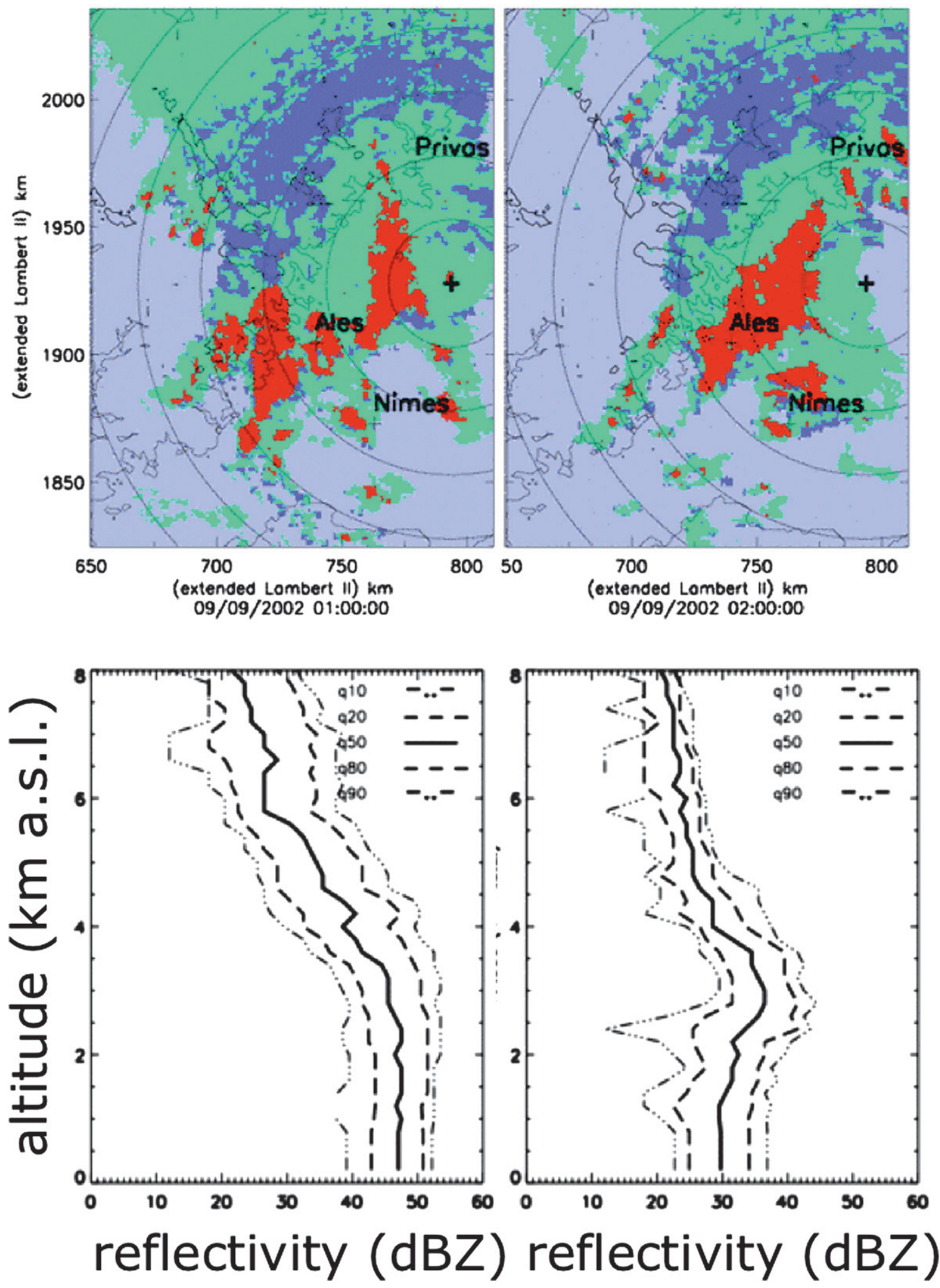

FIG. 2. Results of rain separation for the mesoscale convective system observed at (top left) 0100 UTC and (top right) 0200 UTC 9 Sep 2002: (red, convective rainfall; blue, stratiform rainfall; green, undetermined). (bottom) The 3D variability of the measured reflectivity within the 70-km radar range between 0100 and 0200 UTC 9 Sep 2002 for (left) convective and (right) stratiform conditions. The curves are the $10 \%$, $20 \%, 50 \%, 80 \%$, and $90 \%$ quantiles of the statistical distribution of the measured reflectivity as a function of altitude. 

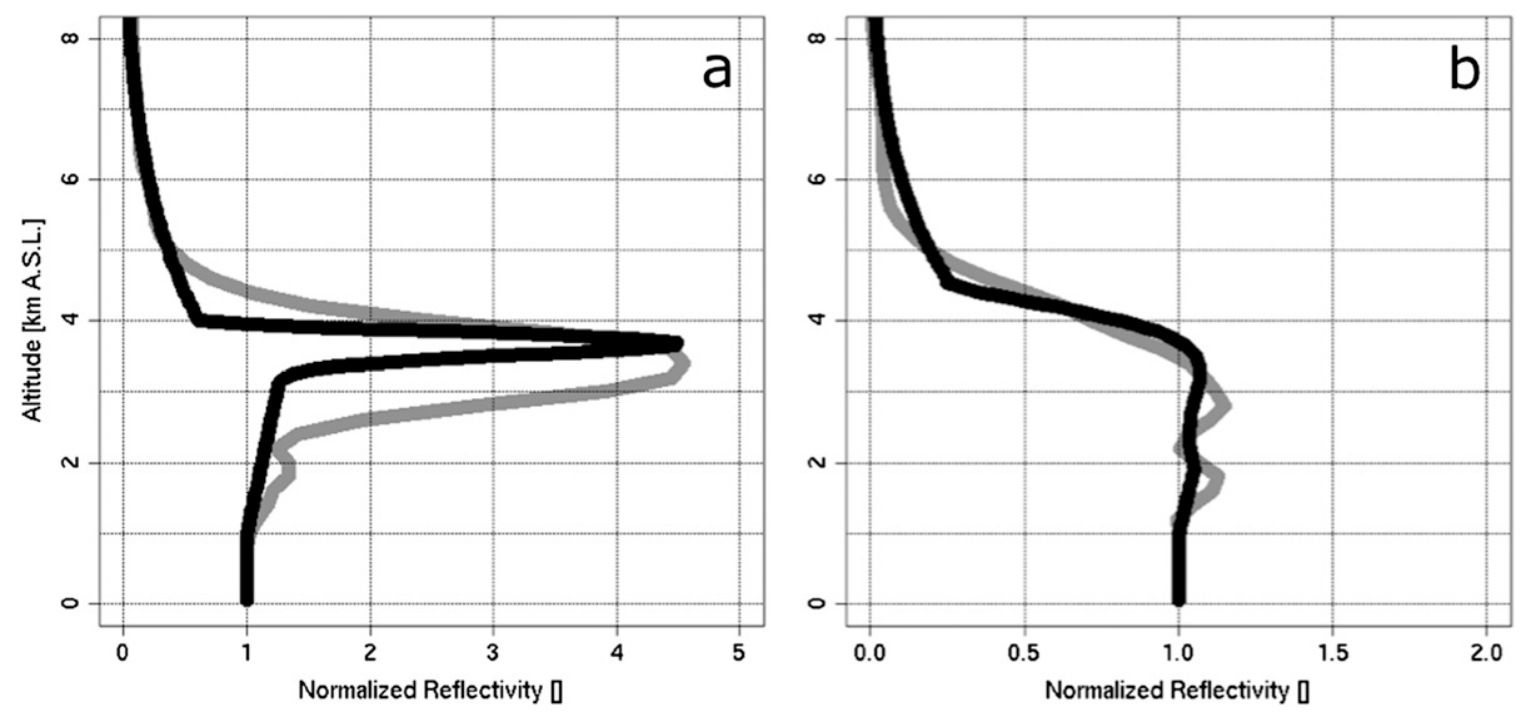

FIG. 3. Vertical profiles of the (a) stratiform and (b) convective normalized equivalent-reflectivity factor. VPRs identified with the TRADHy software from the radar observations between 0100 and 0200 UTC 9 Sep 2002: modeled (black lines) and from Kirstetter et al. (2010) (gray lines).

Within a subset the vectors differ by the measurement conditions, beam diameter, and beam axis altitudes, which depend on the range to the radar $r$ for all elevation angles. Assuming the radar sampling conditions are unchanged within a narrow distance interval $[r-(\Delta r / 2), r+(\Delta r / 2)]$, the vectors $\mathbf{Z}_{\mathrm{em}}$ are averaged within this interval. Kirstetter et al. (2010) considered a moving time window of $1 \mathrm{~h}$ to smooth the observations prior to the VPR identification. In the present paper only the observations of each 5-min radar volume scan are considered. The radar observations thus correspond to a series of vectors $\mathbf{Z}_{\mathrm{em}}(r, \nu)$, where $r$ represents the distance and $\nu$ is the rain type. These vectors when combined depict the vertical variations of the reflectivity smoothed by the radar sampling properties for each rain type. The final step consists in normalizing these observations by the equivalent reflectivity factor at the reference level, which provides the apparent VPR $\mathbf{z}_{\mathrm{ap}}(r, v)$ :

$$
\mathbf{z}_{\mathrm{ap}}(r, v)=\frac{\sum_{i=1}^{N\left(r, v, a_{i}, a_{\mathrm{ref}}\right)} \mathbf{Z}_{\mathrm{em}, i}(r, v)}{\sum_{i=1}^{N\left(r, v, a_{i}, a_{\mathrm{ref}}\right)} \mathbf{Z}_{\mathrm{em}, \mathrm{ref}}(r, v)},
$$

where the values $\mathbf{Z}_{\mathrm{em}, \mathrm{ref}}$ and $\mathbf{Z}_{\mathrm{em}, i}\left(\mathrm{~mm}^{6} \mathrm{~m}^{-3}\right)$ are measured equivalent reflectivity factors for any pair of upper $\left[a_{i}\right.$, with $\left.i \in(1, n-1)\right]$ and reference elevation $\left(a_{\text {ref }}\right)$ angles, respectively. Note that estimating the numerator and denominator of Eq. (6) strictly with the subset of $N\left(r, v, a_{\mathrm{ref}}, a_{i}\right)$ observations available simultaneously for the two elevation angles $a_{i}$ and $a_{\text {ref }}$ is an important condition to avoid biasing the apparent VPRs. A data censoring scheme is applied based on the relative standard deviation of reflectivity ratios (Kirstetter et al. 2010). The apparent VPR may not sample all the altitude intervals homogeneously given the beam characteristics. Observational error must be defined for the extended

TABLE 3. Values of the parameters defining the two VPRs to simulate the observed ones for the 0200 UTC 9 Sep 2002 case, and values of the parameters defining the VPR for EKF initialization for both stratiform and convective cases. The melting-layer thickness and average bulk density of frozen particles $\bar{\rho}_{s}$ is indicated.

\begin{tabular}{lllll}
\hline \hline \multicolumn{1}{c}{ Input parameter } & & \multicolumn{1}{c}{ Convective } & \multicolumn{1}{c}{ Stratiform } & EKF initialization \\
\hline Echo top & $h_{T}$ & $12 \mathrm{~km}$ & $10 \mathrm{~km}$ & $11 \mathrm{~km}$ \\
Upper boundary of the melting layer & $h_{M}$ & $4.6 \mathrm{~km}$ & $4.0 \mathrm{~km}$ & $3.6 \mathrm{~km}$ \\
Density factor & $\gamma_{s}$ & $250\left(907 \mathrm{~kg} \mathrm{~m}^{-3}\right)$ & $25\left(508 \mathrm{~kg} \mathrm{~m}^{-3}\right)$ & $200 . / 15$. \\
Slope of the profile in the liquid layer & $G_{l}$ & $5 \times 10^{-2} \mathrm{~km}^{-1}$ & $6 \times 10^{-2} \mathrm{~km}^{-1}$ & 0 \\
Melting-layer thickness & & $2700 \mathrm{~m}$ & $950 \mathrm{~m}$ & $1 \mathrm{~km}$ \\
Reference level & $h_{0}$ & $1 \mathrm{~km}$ & $1000 \mathrm{~mm}^{6} \mathrm{~m}^{-3}$ & $1 \mathrm{~km}$ \\
Radar reflectivity factor at the reference level $h_{0}$ & $Z_{0}$ & $50118 \mathrm{~mm}^{6} \mathrm{~m}^{-3}$ & - \\
\hline
\end{tabular}


Kalman filter. It is computed from the population of individual apparent VPRs located in the distance interval $[r-(\Delta r / 2), r+(\Delta r / 2)]$ for different azimuth angles. A standard deviation associated with the average value [using Eq. (6)] can be derived that characterizes the dispersion around the average value. The average value is the data for the filter and the standard deviation is accounted for in the data covariance matrix derivation. Details are provided in Kirstetter et al. (2010, section 4c). The apparent VPRs obtained for various distances are finally regrouped in the vector $\mathbf{z}_{\mathrm{ap}}$.

\section{b. Application of the model for VPR identification}

The VPR $z(h, v)$ for the rain typed domain $D_{v}$ can be written as $z(h, v)=\overline{Z(h, v)} / \overline{Z_{0}(v)}$, where $\overline{Z(h, v)}$ and $\overline{Z_{0}(v)}$ are the mean value of the equivalent reflectivity over $D_{v}$ at altitude $h$ and $h_{0}$, respectively. This VPR is modeled by the function $z\left(\bar{Z}_{0}, \varphi, h, v\right)$. For the elevation angle $a_{i}$, the mean reflectivity factor at distance $r$ from the radar can be written

$$
\overline{Z_{i}(r, v)}=\int_{H^{-}\left(\theta_{0}, a_{i}\right)}^{H^{+}\left(\theta_{0}, a_{i}\right)} b^{4}\left(\theta_{0}, s\right) \overline{Z(s, v)} d s,
$$

where $b^{4}\left(\theta_{0}, s\right)$ is the two-way normalized power-gain function of the radar antenna at altitude $h$, corresponding to range $r$ and elevation angle $a_{i} ; \theta_{0}$ is the 3 -dB beamwidth while $H^{-}$and $H^{+}$denote the lower and upper limits of the radar beam, respectively. Given Eq. (5), Eq. (7) may be rewritten as

$$
\overline{Z_{i}}(r, v)=\int_{H^{-}\left(\theta_{0}, a_{i}\right)}^{H^{+}\left(\theta_{0}, a_{i}\right)} b^{4}\left(\theta_{0}, s\right) \overline{Z_{0}(v)} z\left[\overline{Z_{0}(v)}, \varphi, s, v\right] d s .
$$

Thus the apparent VPR can be modeled as

$$
\mathbf{z}_{\mathrm{ap}}\left(r, v, a_{\mathrm{ref}}, a_{i}\right)=\frac{\int_{H^{-}\left(\theta_{0}, a_{i}\right)}^{H^{+}\left(\theta_{0}, a_{i}\right)} b^{4}\left(\theta_{0}, s\right) z\left[\overline{Z_{0}(v)}, \boldsymbol{\varphi}, s, v\right] d s}{\int_{H^{-}\left(\theta_{0}, a_{\mathrm{ref}}\right)}^{H^{+}\left(\theta_{0}, a_{\mathrm{ref}}\right)} b^{4}\left(\theta_{0}, s\right) z\left[\overline{Z_{0}(v)}, \boldsymbol{\varphi}, s, v\right] d s} .
$$

This model, denoted $\mathbf{z}_{\mathrm{ap}}=g(\varphi)$, expresses the relation between a series of apparent VPRs computed over the domain $D_{v}$ and the physical parameters $\varphi$. It results from the coupling between the physically based VPR model described in section 2 and the radar sampling characteristics. The VPR identification consists of retrieving the parameters $\varphi$ that best reconstitute the observed apparent VPRs according to $g$.
The VPR depends on $\overline{Z\left(h_{0}, v\right)}$, mean value of reflectivity factor at the reference level, which is not known and depends on the identified VPR. This practical problem can be solved by assuming that $\overline{Z\left(h_{0}, v\right)}$ is correctly estimated by the mean value of the radar measurements over the identification domain at the lowest tilt. A sensitivity study (section 5) shows that the VPR shape as defined in Eq. (5) is weakly sensitive to the equivalent reflectivity at the reference level.

\section{c. Application of the extended Kalman filter to the VPR identification}

The use of a Kalman filter is appealing for VPR identification because (i) it identifies the vector state consistent with observations at any time and (ii) it accounts for the temporal continuity of the process to be represented. The Kalman filter is a classical estimation method initially developed for linear systems and further extended to nonlinear systems (Gelb 1974). Here we use the extended Kalman filter, adapted to weakly nonlinear systems with a limited number of parameters. The VPR identification can be considered as a nonlinear finite dimensional discrete time system of the form

$$
\begin{aligned}
\boldsymbol{\varphi}_{k+1} & =f\left(\boldsymbol{\varphi}_{k}\right)+\boldsymbol{\varepsilon}_{k} \\
\mathbf{z}_{\mathrm{ap}, k} & =g\left(\boldsymbol{\varphi}_{k}\right)+\boldsymbol{\omega}_{k},
\end{aligned}
$$

where the state vector of the system at time $t_{k}$ groups the parameters defining the VPR characteristics $\boldsymbol{\varphi}_{k}=\left(G_{l}, h_{T}, h_{M}, \gamma_{s}\right)_{k}$ with $n_{\varphi}=4$ components; $\mathbf{z}_{\mathrm{ap}, k}$ is the vector regrouping the $n_{z}$ observations (apparent VPRs) at time $t_{k} ; \boldsymbol{\varepsilon}_{k}$ is the modeling error; $\boldsymbol{\omega}_{k}$ is an observation error (section 4a); and $f$ (defined below) and $g$ [Eq. (9)] are nonlinear vector functions of the state $\varphi$. In addition, it is assumed that $\boldsymbol{\varepsilon}_{k}$ and $\boldsymbol{\omega}_{k}$ are Gaussian random variables with means and covariances $\mathbf{Q}_{k}$ and $\mathbf{R}_{k}$, respectively, assumed to be zero and independent from each other.

In that context, the EKF reproduces the system evolution by accounting for the model prediction and the observations. The estimate of the system state at time $t_{k+1}$ can be obtained by combining two values: the state equation at time $t_{k}$ and the observation performed at time $t_{k+1}$. The EKF proceeds in two steps:

1) The forecasting step at time $t_{k+1}$ knowing the system state at time $t_{k}$ :

$$
\varphi_{k+1}^{f}=f\left(\boldsymbol{\varphi}_{k}^{u}\right) \text { and } \mathbf{P}_{k+1}^{f}=\mathbf{F}_{k} \mathbf{P}_{k}^{u} \mathbf{F}_{k}^{\mathrm{T}}+\mathbf{Q}_{k} \text {, }
$$

where $\varphi_{k}^{u}$ is the vector state at time $t_{k}$ and $\mathbf{P}_{k}^{u}$ is its associated error covariance matrix; $\boldsymbol{\varphi}_{k+1}^{f}$ is the 
forecast vector state at $t_{k+1}$ and $\mathbf{P}_{k+1}^{f}$ is its associated error, and $\mathbf{F}_{k}=\left[d f\left(\boldsymbol{\varphi}_{k}\right) / d \boldsymbol{\varphi}_{k}\right]$ is the matrix of the partial derivatives of the state equation at time $t_{k}$.

2) The system updating at time $t_{k+1}$, which combines the forecasting and the observation according to their accuracy:

$$
\boldsymbol{\varphi}_{k+1}^{u}=\boldsymbol{\varphi}_{k+1}^{f}+\mathbf{K}_{k+1}\left[\mathbf{z}_{\mathrm{ap}, k+1}-g\left(\boldsymbol{\varphi}_{k+1}^{f}\right)\right]
$$

and

$$
\begin{aligned}
& \mathbf{K}_{k+1}=\mathbf{P}_{k+1}^{f} \mathbf{G}_{k+1}^{\mathrm{T}}\left(\mathbf{R}_{k+1}+\mathbf{G}_{k+1} \mathbf{P}_{k+1}^{f} \mathbf{G}_{k+1}^{\mathrm{T}}\right)^{-1} \\
& \mathbf{P}_{k+1}^{u}=\left(\mathbf{I}-\mathbf{K}_{k+1} \mathbf{G}_{k+1}\right) \mathbf{P}_{k+1}^{f},
\end{aligned}
$$

where $\boldsymbol{\varphi}_{k+1}^{u}$ is the final "updated" estimate of the state vector at time $t_{k+1}, \mathbf{K}_{k+1}$ is the EKF gain at time $t_{k+1}$, and $\mathbf{G}_{k}=\left[\operatorname{dg}\left(\boldsymbol{\varphi}_{k}\right) / d \boldsymbol{\varphi}_{k}\right]$ is the matrix of the partial derivatives of the observation equation at time $t_{k+1}$. The partial derivatives of the observation equation $\mathbf{G}_{k}$ are numerically calculated (and updated) at each cycle of the Kalman filter.

Equation (13) expresses the error reduction due to the addition of new information into the system from observations at time $t_{k+1}$. The error decreases as a function of the accuracy (related to $\mathbf{R}_{k+1}$ ) and the quantity of observations available at each analysis cycle. In the case of a linear system, it can be shown that the state update $\boldsymbol{\varphi}_{k+1}^{u}$ is optimal in the least squares sense. For nonlinear systems, the filter is suboptimal.

The EKF is applied in assuming that the VPR is constant between two successive time steps. The state model is reduced to a steady state $\varphi_{k+1}^{f}=\varphi_{k}^{u}$, which defines the function $f$. This assumption means that the VPR representing a rain type changes slowly during a time increment. This is a reasonable assumption if the time increment is short compared to the rain field evolution and if the VPR to determine is representative of a large area. The forecasting step assumes a constant VPR between time $t_{k}$ and time $t_{k+1}$ and is corrected by the updating step based on the radar observations at time $t_{k+1}$. In that particular case the Kalman filter increases the stability of the VPR identification by accounting for the memory of the VPR evolution. We are aware that the steady-state equation, convenient for short time increments, is not fully satisfying and might be enriched by different ways. Future studies will address this specific point.
The error covariance matrices control the confidence granted to the forecasting and updating processes. They play an important role in this application of the method. We consider the errors between the data (the components of the apparent VPRs) to be independent, which means that the observation error covariance matrix $\mathbf{R}_{k}$ is diagonal. A sensitivity analysis on the covariance matrix of error of the data (not shown here) confirmed the findings from Vignal et al. (1999) that both horizontal and vertical covariance on data errors exert a negligible influence on the Kalman filter. This can be explained by the good continuity of apparent VPRs, both in distance and in altitude. The error covariance between the parameters is also needed. Because we set up models describing the maximum of variability in the vertical structure of convective and stratiform rainfall with as few parameters as possible, parameters are expected to be uncorrelated, as is the error of their a priori values. In the context of the present study, we chose to simplify the approach by considering the errors on the VPR parameters to be independent. The covariance matrices $\mathbf{P}_{k}$ and $\mathbf{Q}_{k}$ are therefore diagonal.

We quantify the accuracy of the steady-state assumption, on which the system evolution is based, by computing the mean relative quadratic error (MRQE) between the data observed at times $t_{k+1}$ and the simulated relative apparent VPRs associated with $\varphi_{k}^{f}$ :

$$
\operatorname{MRQE}_{k}=\frac{1}{n_{z}} \sum_{i=1}^{n_{z}}\left[\mathbf{z}_{\mathrm{ap}, i}-g\left(\varphi_{k}^{f}\right)\right]^{2},
$$

where $n_{z}$ is the number of observations. An increase of MRQE can be analyzed as a degradation of the steadystate assumption validity. The error of the steady-state forecasting equation, defined by $\mathbf{Q}_{k}$, is adjusted as follows:

$$
\mathbf{Q}_{k+1}=\left(a \times \mathrm{MRQE}_{k+1}+b\right) \mathbf{P}_{k}^{a},
$$

where $a$ and $b$ are constant parameters (section 5b).

\section{Application of the VPR identification}

The proposed VPR identification method is applied to the case study described in section 3 from 1100 UTC 8 September to 1100 UTC 9 September. The temporal resolution $\Delta T$ is equal to the volume scan period: $t_{k}=t_{k-1}+\Delta t$. The parameters are initialized the same for both convective and stratiform cases (see Table 3) except for the density parameter, $\gamma_{s}$ : it is 200 for the convective regime and 15 for the stratiform regime. The covariances of parameters are initialized with large values consistent with our lack of knowledge of the 

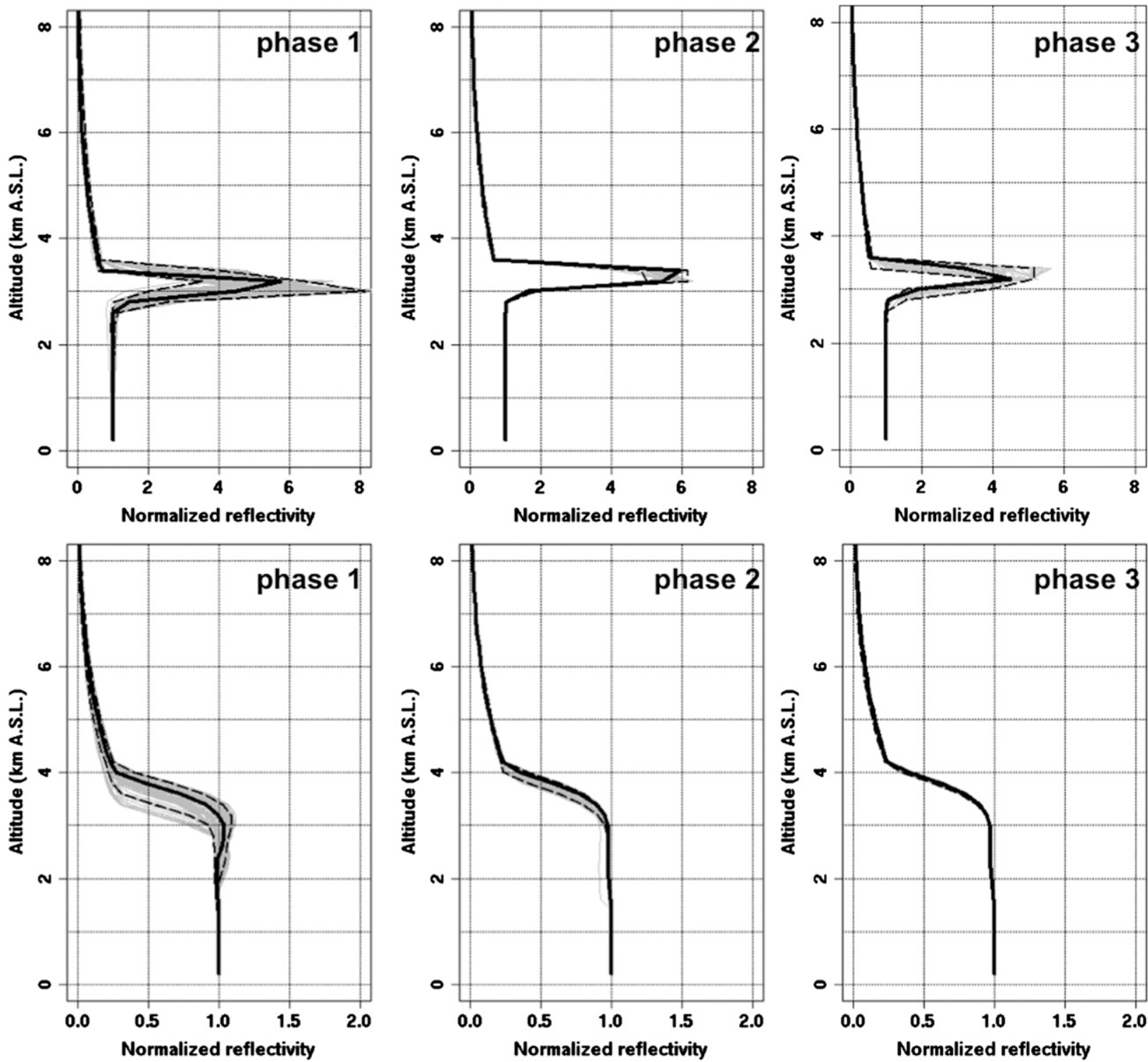

FIG. 4. (top) Stratiform and (bottom) convective VPRs (gray curves) for the three phases of the 8-9 Sep 2002 rainfall event. The $10 \%$, $50 \%$, and $90 \%$ quantiles of the VPR distribution are displayed with dashed, solid, and dashed black lines, respectively.

initial system state. To determine accurate conditions for application of the Kalman filter, sensitivity tests are performed around default parameter values. The influence of the reflectivity factor at the reference level $Z_{0}$ on the identified values of the VPR parameters is studied. The influence of the parameters $a$ and $b$ defining the forecast error is also tested. Finally, some insight on the consistency of the identified parameters is provided.

\section{a. Retrievals}

The identified VPR distributions for the successive time steps of the 8-9 September 2002 event are displayed in Fig. 4. The rain-typed VPR populations (convective versus stratiform) are naturally very distinct. Qualitative improvements are noted for the stratiform VPRs when comparing with the previous method (Kirstetter et al. 2010, Figs. 5 and 6) where the radar beam-smoothing effects cause the bright band to be high $(1200 \mathrm{~m})$ relative to values mentioned in the literature $(700 \mathrm{~m}$ or lower) from vertically pointing radar observations (e.g., Fabry and Zawadzki 1995). The VPRs present a finer bright band consistent with the physical constraints introduced by a stratiform melting-layer model extensively validated against vertical pointer data (e.g., Zawadzki et al. 2005; 
Heyraud et al. 2008). The proposed approach significantly mitigates the radar beam-smoothing effects.

Much less variability is noted from these VPR distributions than with the previous method (Kirstetter et al. 2010). Aggregating data from several successive (1 h) time steps was necessary to stabilize the VPR identification. In the present method the radar data are not smoothed and present more variability, which is more challenging. This demonstrates that the current method is more robust than the older one. Another advantage is that we no longer assume that the VPR remains spatially homogeneous at an hourly time step inside each type of rain zone. By ensuring the temporal consistency of the parameters, the formulation of the VPR identification in the framework of a Kalman filter insures the continuity of the VPR from a time step to the next one. It provides enhanced robustness in dealing with various radar sampling conditions, different rain types, and noisy radar observations, as well as preventing the temporal instabilities noted in the previous approaches (Kirstetter et al. 2010). As shown in Fig. 5, the temporal variations of VPR during the rain event are linked to the variations of the parameters $\boldsymbol{\varphi}=\left(G_{l}, h_{T}, h_{M}, \gamma_{s}\right)$.

\section{b. Sensitivity analyses}

To define accurate conditions for running the Kalman filter, a sensitivity analysis is performed on the forecast error, that is, on the parameters $a$ and $b$ [Eq. (15)]. Values of $a$ ranging from 0.01 to 1 are tested while $b$ is fixed at $b=0.001$. Representative results are shown in Fig. 6. Small forecast errors are associated with a smoothed filter's trajectory showing limited variability. On the contrary, high forecast errors result in high (and quite physically unrealistic) temporal variability of parameters, probably influenced by strong or noisy fluctuations of the observed data. Note as a sign of stability that the boundaries allowed for parameters (see Table 2) are not reached during the run of the Kalman filter. For both convective and stratiform types a balance between temporal adaptability to the radar measurements and physical consistency is found with $a=0.1$ (see Fig. 5).

Let us recall that the VPR models account for reflectivity factor at the reference level $Z_{0}$. To check the representativeness of the identified VPR parameters to the data at each identification cycle, it is important to assess the influence of $Z_{0}$. A sensitivity analysis is performed with $a=0.1$ and $b=0.001$ as accurate values for the forecast error. According to the observations (Fig. 2) and the criteria from Steiner et al. (1995) and SanchezDiezma et al. (2000), we consider $Z_{0}$ values ranging from 20 to $40 \mathrm{~dB} Z$ for stratiform and $Z_{0}$ values ranging from 35 to $55 \mathrm{~dB} Z$ for convective. The PDFs of VPRs from the standard run corresponding to Fig. 4 and the runs from the sensitivity analysis are shown in Fig. 7. They present much similarity so the VPRs identified within the Kalman filter do not significantly diverge from each other. We therefore may assume the method does not significantly depend on $Z_{0}$.

\section{c. The estimation covariance matrix}

The robustness of the identification is assessed with the estimation variance of the parameters. Table 4 provides the mean of the analysis standard deviation, expressed in percentage of the allowed interval range for each parameter. The robustness of the identification is generally good as the standard deviation is generally lower than $10 \%$ of the interval range. The echo top $h_{T}$ shows lowest scores with standard deviation of at least $20 \%$ : this parameter presents the highest estimation variances. Two reasons could explain this fact: (i) the VPR model provides a lower accurate description of upper parts of the VPR as seen by radar or (ii) compared to other parameters, radar data are not informative enough to enable a robust identification of $h_{T}$. As our objective lies in lower altitudes, we do not consider this fact to be significant. Nevertheless, we intend to address this issue in future research. The upper boundary of the melting layer is for both types associated with the more robust identification (standard deviation lower than $2 \%$, i.e., $200 \mathrm{~m}$ in altitude). It is noteworthy that the identification is globally more robust in the stratiform case than in the convective case. In fact, identification of the VPR features is easier with a bright band that allows a good identification of the characteristic altitudes and the melting layer.

\section{d. Physical consistency of the VPR parameters identification}

The global consistency of the identification is first analyzed in terms of differences between convective and stratiform (Fig. 5). Despite an identical initialization, the identified altitudes for both rain types rapidly reach distinct values within 10 cycles of the Kalman filter and present relative physical consistency. The top of the precipitating cloud is higher in the convective case (mean value around $11500 \mathrm{~m}$ ) than in the stratiform case (starting from $8000 \mathrm{~m}$ and increasing slowly up to $11000 \mathrm{~km}$ during the event). This is consistent with Adler and Mack (1984) who connect the ground intensity (bound with $Z_{0}$ by a $Z-R$ relationship) and the radar echo top. The top of melting layer is also higher in the convective case (mean value around $4200 \mathrm{~m}$ ) than in the stratiform case (mean value lower than $3600 \mathrm{~m}$ ). This is consistent with the impact of updrafts in the convection. For the stratiform case, this parameter may be compared to the Interim European Centre for Medium-Range Weather 

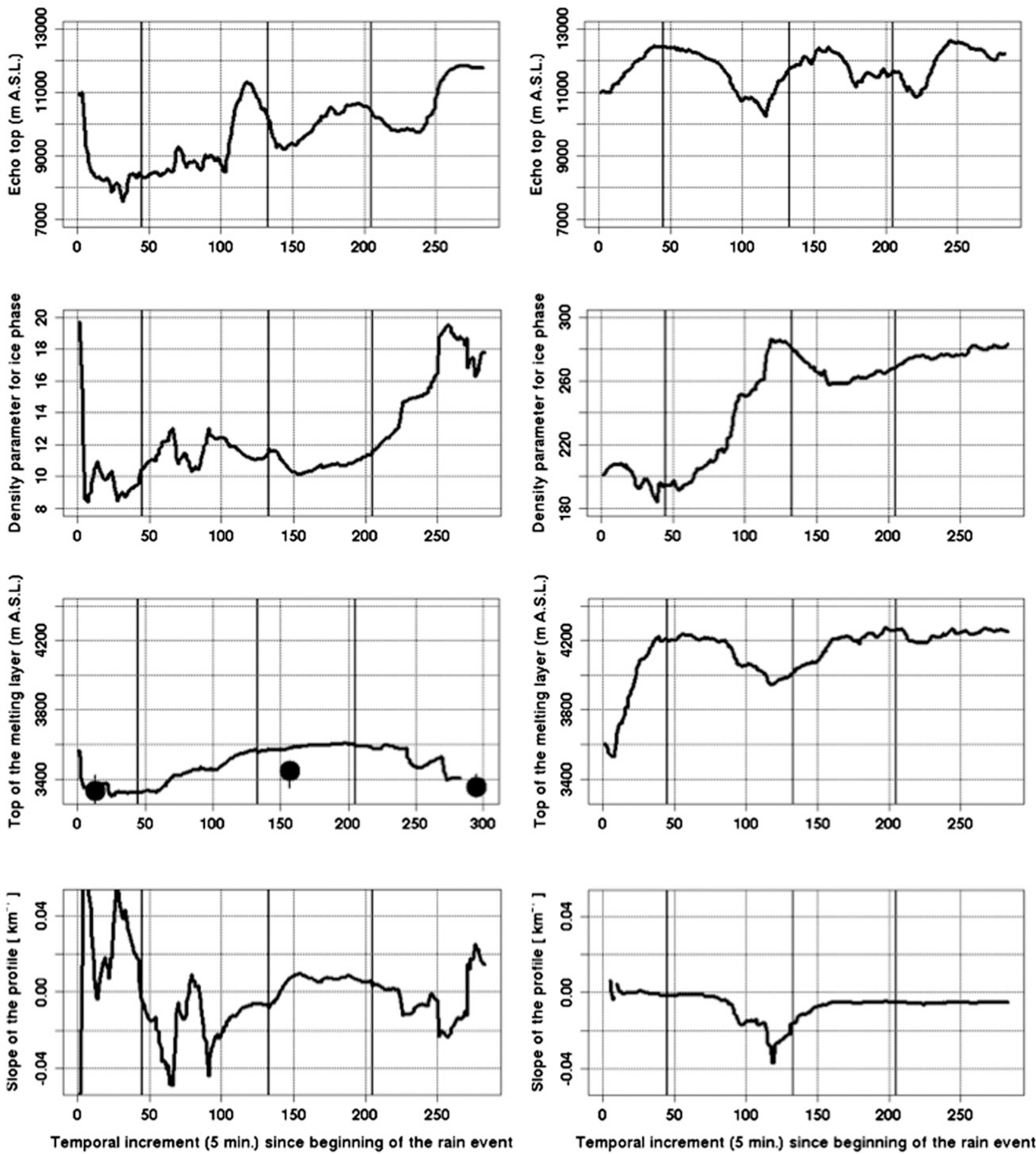

FIG. 5. Temporal evolution of the five identified parameters for the (left) stratiform and (right) convective cases during the 8-9 Sep rain event: (top to bottom) $h_{T}, \gamma_{s}, h_{M}$, and $G_{l}$. For the stratiform $h_{M}$, The large dots are the mean values of the ERA-Interim reanalyses with the short vertical lines on the dots indicating the interval range.

Forecasts (ECMWF) Re-Analysis (ERA-Interim; Dee et al. 2011). The mean $0^{\circ} \mathrm{C}$ isotherm altitude is computed in the zone where most stratiform rain occurred [domain defined by longitude $\left(3.60^{\circ}-5.44^{\circ}\right)$ and latitude $\left(44.61^{\circ}-\right.$ $\left.\left.45.75^{\circ}\right)\right]$. The $h_{M}$ parameter for stratiform part is within
$100 \mathrm{~m}$ of the ERA-Interim reanalysis values (around $3400 \mathrm{~m}$ ) and presents the same temporal variations. The density factor is coherent with the rain type, with mean values of 12 (densities $\bar{\rho}_{s}$ around $280 \mathrm{~kg} \mathrm{~m}^{-3}$ representative of snow) for stratiform and 250 (densities $\bar{\rho}_{s}$ 

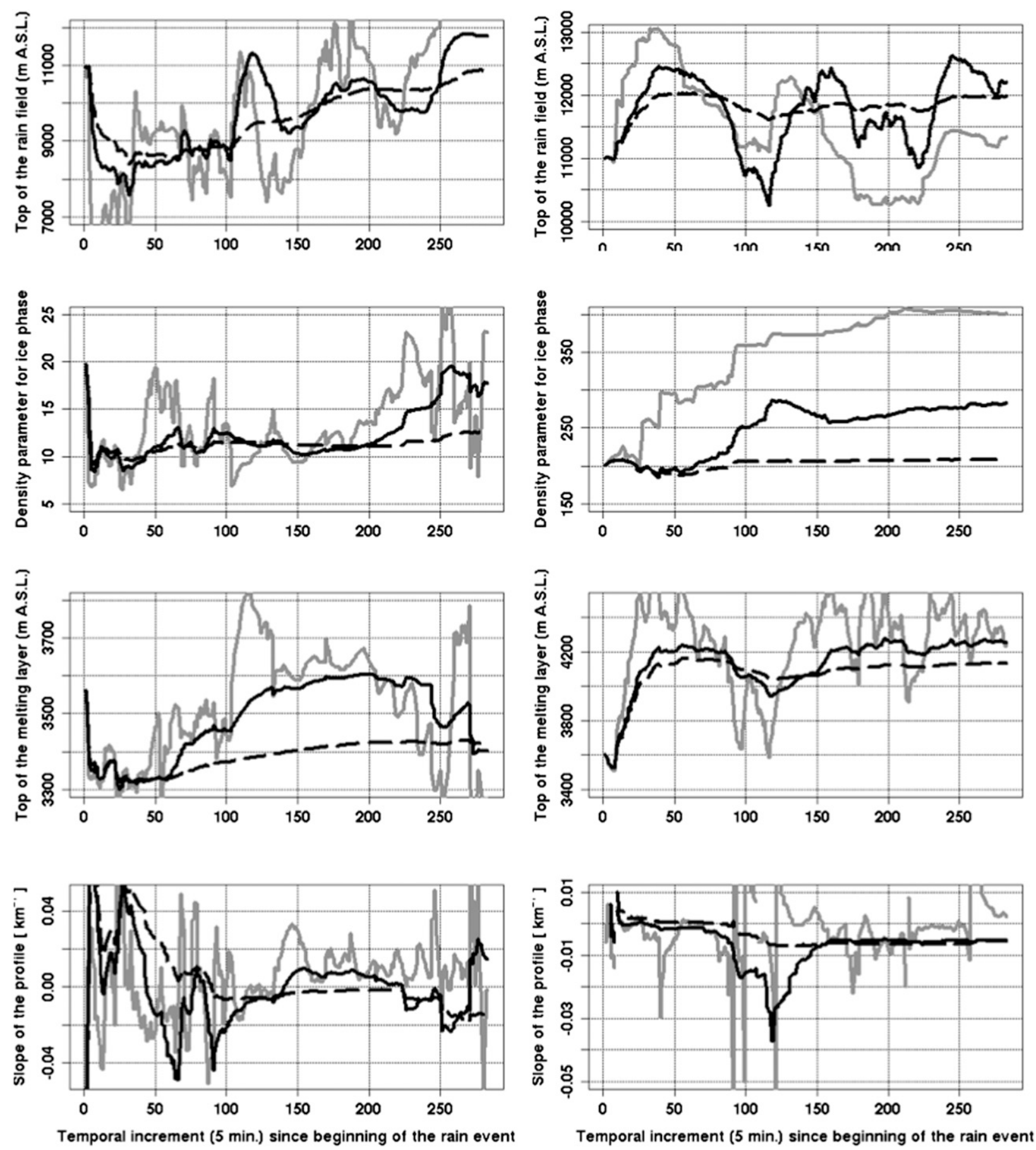

FIG. 6. Sensitivity analysis of the VPR retrieval to the forecast error. The curves show the temporal evolution of the parameters for the (left) stratiform and (right) convective cases during the 8-9 Sep rain event: (top to bottom) $h_{T}, \gamma_{s}, h_{M}$, and $G_{l}$. The curves correspond to $a=0.00$ (dashed line), 0.10 (solid line), and 1.00 (gray line).

around $900 \mathrm{~kg} \mathrm{~m}^{-3}$ representative of graupel/hail) for convective. One may note the high values for convective density and see here an indication of the imperfect description of frozen particles in the convective model. We intend to address this issue in future research. The slope of the profile in the liquid phase shows also a clear signal separating convective and stratiform VPRs. The values are often positive for the stratiform, a possible indication of evaporation, which acts to lower the water content and the number of biggest drops mostly contributing to the 

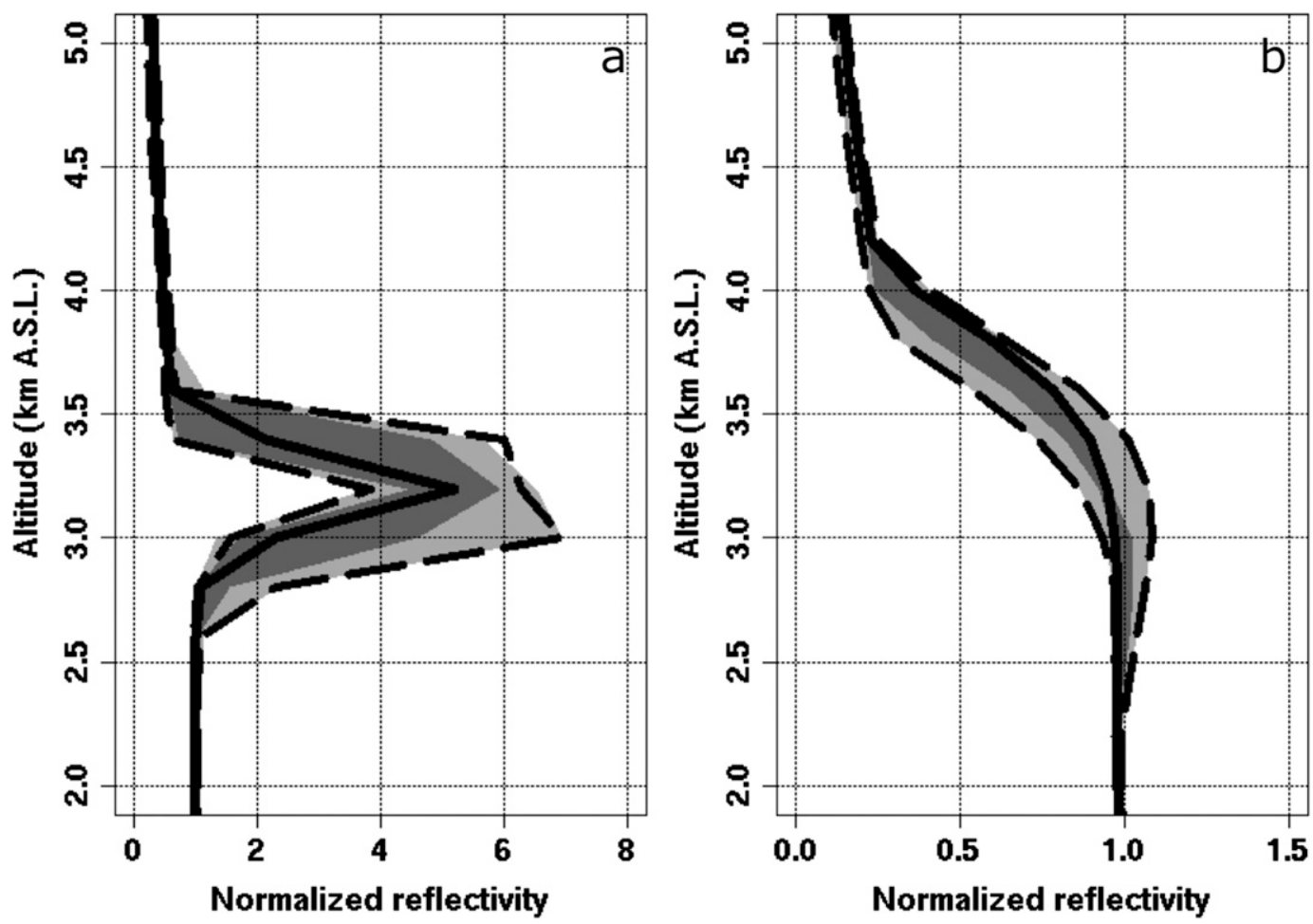

FIG. 7. PDFs of (a) stratiform and (b) convective VPRs for the 8-9 Sep 2002 rainfall event: median (0.5 quantile, thick black line) and the 0.1 and 0.9 quantiles (the two dashed lines). The distribution of VPRs from the $Z_{0}$ sensitivity study is shaded, with the dark-gray region representing the area between the 0.25 and 0.75 quantiles and the light-gray region representing the area between the 0.1 and 0.9 quantiles.

radar signal in the course of falling hydrometeors. The values are negative in the convective part, indicating increasing water content and/or increasing of the number of biggest drops in the course of falling hydrometeors.

We now analyze the temporal evolution of the parameters. The three phases of the 8-9 September 2002 rain event are emphasized in Fig. 5. They distinguish by separated state vector $\varphi$ and corresponding VPRs (see Fig. 4). The evolution of the convective top of the precipitating cloud follows the dynamics of the rain event. Two enhancements are noted during the mature phase and the passage of the cold front. The evolution of the top of the melting layer for the stratiform part (freezing level) shows also temporal consistency. Values around $3400 \mathrm{~m}$ in the development phase are followed by an enhancement to $3600 \mathrm{~m}$ in the phase of active convection probably because of latent heating release by convection. A final decrease is associated with the passage of the cold front. This pattern is consistent with the radiosounding measurements from Nîmes and ERA-Interim analysis. The density parameter of the stratiform case presents an increase in the last phase, a possible indication of the disorganization of the "MCS type" rain field with the passage of the cold front. The interpretation of the other parameters is not so straightforward. We may note that the slope of the stratiform VPR becomes positive during the mature phase, which may be a signature of increasing evaporation in the stratiform area.

The rough consistency of these elements may be seen as an indication of validity for the description of the precipitation field of 8-9 September 2002 rain event with the VPR models.

\section{Conclusions}

A VPR identification method based on simple VPR models is presented. It accounts for the radar sampling and is applied on rain data of homogeneous type. In

TABLE 4. Mean of the updated standard deviation, expressed in percentage of the allowed interval range for each parameter (see Table 2).

\begin{tabular}{|c|c|c|c|}
\hline Input parameter & & Convective & Stratiform \\
\hline Echo top & $h_{T}$ & 48 & 20 \\
\hline Density factor & $\gamma_{s}$ & 13 & 0.4 \\
\hline Upper boundary of the melting layer & $h_{M}$ & 2 & 0.4 \\
\hline Slope of the profile in the liquid layer & $G_{l}$ & 2 & 5 \\
\hline
\end{tabular}


comparison with the original TRADHy method (Kirstetter et al. 2010), new physically based constraints are introduced and the number of parameters is considerably lowered (from 60 to 4). It presents the following advantages: (i) it is easier to control, (ii) it improves the physical consistency of the identified VPR, and (iii) it enables a physical insight into the rainfall field. The VPR inference is time-adjusted in the framework of an extended Kalman filter. This approach allows assimilating new radar observations to continuously update the VPR characteristics and ensures the temporal consistency of the parameters defining the VPR. A first guess (e.g., range-weighted VPR) is no longer necessary, nor is any time aggregation of rain data required to smooth the observations. The new method is therefore more robust and much less time consuming.

The method enables us to check the physical consistency of the retrieved VPR. Positive results have been obtained compared to the previous method, insofar as the physically based identified VPR (i) presents physically consistent shapes and better characteristics than the previous VPR considering beam effects, (ii) shows improved robustness in the difficult radar measurement context of the Cévennes-Vivarais region, and (iii) provides consistent physical insight into the rain field.

More detailed physical descriptions of the vertical structure of rainfall could be introduced in future research. The proposed 1D model for the vertical variations of the equivalent reflectivity factor is based on a simplified representation of the melting layer with no air vertical motion. While this is probably accurate for the stratiform case, more research is certainly needed to account for the vertical air motion for the convective case in future works. From the diagnostic of the parameter variance (section $5 \mathrm{c}$ ) there is room for improvement in the description of the frozen region. The Kalman filter is run assuming a steady-state VPR and the VPR evolution is controlled by the observations. An interesting improvement would consist in introducing a modeled VPR evolution provided for instance by a meteorological model. Moreover, it would be worthwhile to assess the interest of radar polarization techniques in improving determination of the $0^{\circ} \mathrm{C}$ isotherm altitude and better distinguishing hydrometeors types. Also, the explicit identification of the various states of water particles (liquid, solid, and melting) is of interest for vertically integrated liquid content estimation (VIL; Boudevillain and Andrieu 2003) and bridging between radars operating at various wavelengths.

Acknowledgments. This work was funded by the FP6 HYDRATE STREP (GOCE 037024) of the European Community, a postdoctoral grant from the Centre National
d'Études Spatiales, and a postdoctoral grant from the NASA Global Precipitation Measurement mission Ground Validation Management. The study documented in this paper began when the first author was a doctoral student at the Laboratoire d'étude des Transferts en Hydrologie et Environnement, Grenoble, France. The first author thanks Nicolas Viltard and Yvon Lemaitre for their fruitful comments on the mesoscale convective systems dynamics.

\section{APPENDIX}

\section{Scaling Formalism of the DSD Using the Reflectivity Factor as the Reference Variable}

To describe the PSD, the gamma distribution is used with the following scaled formulation involving the total concentration $N_{t}\left(\mathrm{~m}^{-4}\right)$, a characteristic diameter $D_{0}(\mathrm{~m})$, and a dimensionless parameter $\mu$ (Uijlenhoet et al. 2003a,b; Yu et al. 2012, manuscript submitted to J. Appl. Meteor. Climatol.):

$$
N(D)=\frac{\mathrm{N}_{\mathrm{t}}}{D_{0}}\left\{\frac{(4+\mu)^{1+\mu}}{\Gamma(\mu+1)}\left(\frac{D}{D_{0}}\right)^{\mu} \exp \left[-(4+\mu) \frac{D}{D_{0}}\right]\right\} .
$$

The term between curly braces is the gamma PDF of the scaled diameter $D / D_{0}$; it involves the complete gamma function $\Gamma$.

According to the scaling-law formalism to describe the relationship between the PSD and the radar reflectivity factor in the liquid layer,

$$
N(D, Z)=Z^{\alpha} g_{Z}\left(D Z^{-\beta_{Z}}\right)
$$

where $N(D, Z) d D\left(\mathrm{~m}^{-3}\right)$ is the mean number of raindrops with diameters between $D$ and $D+d D$ present per unit volume of air as a function of the reflectivity factor $Z\left(\mathrm{~m}^{6} \mathrm{~m}^{-3}\right), \alpha_{Z}$ and $\beta_{Z}$ (dimensionless) are scaling exponents, and $g_{Z}(x)$ is a scaled raindrop size distribution as a function of the scaled raindrop diameter $x=D Z^{-\beta_{Z}}$. The subscript $Z$ indicates the choice of the reflectivity factor as the reference variable; for a development of the scaling formalism with the rain rate see Sempere-Torres et al. (1994, 1998), Porrà et al. (1998), Uijlenhoet (1999, 2001), and Uijlenhoet et al. (2003a,b). According to this formulation $g_{Z}(x)$ has no functional dependence on the value taken by $Z$. The self-consistency constraints guarantee that substitution of the parameterization for the raindrop size distribution [Eq. (A2)] into the defining expression for the reflectivity factor $Z$ (sixth moment of the distribution) leads to $Z=Z$ : 


$$
Z=\int_{\Omega_{D}} Z^{\alpha_{Z}} g_{Z}\left(D Z^{-\beta_{Z}}\right) D^{6} d D
$$

This implies the following relations:

$$
\left\{\begin{array}{l}
\alpha_{Z}+7 \beta_{Z}=1 \\
\int_{\Omega_{D}} x^{6} g_{Z}(x) d x=1
\end{array} .\right.
$$

The quantity $g_{Z}(x)$ must satisfy an integral equation (which reduces its degrees of freedom by one) and there is only one free scaling exponent. For a gamma parameterization, the scaled raindrop size distribution is

$$
g_{Z}(x)=K_{Z} x^{\mu} \exp \left(-\lambda_{Z} x\right) .
$$

The $\mu$ (dimensionless) is the shape parameter of the gamma distribution, and $K_{Z}\left(\mathrm{~m}^{1-3 \beta_{Z}}\right)$ and $\lambda_{Z}\left(\mathrm{~m}^{1-3 \beta_{Z}}\right)$ are the scaled distribution parameters. To be an admissible description of the scaled raindrop size distribution, $g_{Z}(x)$ must satisfy the self-consistency constraints. By combining Eqs. (A4) and (A5) the last yield a power-law relationship of $K_{Z}$ in terms of $\lambda_{Z}$ :

$$
\left\{\begin{array}{l}
\alpha_{Z}+7 \beta_{Z}=1 \\
K_{Z}=\frac{\lambda_{Z}}{\Gamma(7+\mu)}
\end{array} .\right.
$$

The self-consistency constraints imply a relation between the scaling exponents and a relation between the distribution parameters. An expression of the gamma PSD is obtained through combining Eqs. (A6), (A5), and (A2):

$$
N(D, Z)=\frac{\lambda_{Z}^{7+\mu}}{\Gamma(7+\mu)} Z^{1-(7+\mu) \beta_{Z}} D^{\mu} \exp \left(-\frac{\lambda_{Z}}{Z^{\beta_{Z}}} D\right)
$$

Any PSD bulk variable (written here for the $k$ th-order moment $M_{k}$ )

$$
M_{k}=\int_{\Omega_{D}} N(D, Z) D^{k} d D
$$

may be expressed as a function of the scaling moment $Z$ and the PSD parameters by combining Eqs. (A8) and (A7):

$$
M_{k}=\frac{\Gamma(\mu+k+1)}{\Gamma(\mu+7)} \lambda_{Z}^{6-k} Z^{1-(6-k) \beta_{Z}} .
$$

\section{REFERENCES}

Adler, R. F., and R. A. Mack, 1984: Thunderstorm cloud heightrainfall rate relations for use with satellite rainfall estimation techniques. J. Appl. Meteor., 23, 280-296.

Andrieu, H., and J. D. Creutin, 1995: Identification of vertical profiles of radar reflectivity using an inverse method. Part I: Formulation. J. Appl. Meteor., 34, 225-239.

— G. Delrieu, and J. D. Creutin, 1995: Identification of vertical profiles of radar reflectivity using an inverse method. Part II: Sensitivity analysis and case study. J. Appl. Meteor., 34, 240-259.

Bellon, A., G. W. Lee, and I. Zawadzki, 2005: Error statistics of VPR corrections in stratiform precipitation. J. Appl. Meteor., 44, 998-1015.

,$- \ldots$, A. Kilambi, and I. Zawadzki, 2007: Real-time comparisons of VPR-corrected daily rainfall estimates with a gauge mesonet. J. Appl. Meteor., 46, 726-741.

Berne, A., G. Delrieu, H. Andrieu, and J. D. Creutin, 2004: Influence of the vertical profile of reflectivity on radar-estimated rain rates at short time steps. J. Hydrometeor., 5, 296-310.

Bonnifait, L., G. Delrieu, M. Le Lay, B. Boudevillain, A. Masson, P. Belleudy, E. Gaume, and G. M. Saulnier, 2009: Distributed hydrologic and hydraulic modelling with radar rainfall input: Reconstruction of the 8-9 September 2002 catastrophic flood event in the Gard region, France. Adv. Water Resour., 32, 10771089.

Borga, M., F. Tonelli, R. J. Moore, and H. Andrieu, 2000: Longterm assessment of bias adjustment in radar rainfall estimation. Water Resour. Res., 38, 1226, doi:10.1029/2001WR000555.

Boudevillain, B., and H. Andrieu, 2003: Assessment of vertically integrated liquid (VIL) water content radar measurement. J. Atmos. Oceanic Technol., 20, 807-819.

Brown, P. R. A., and P. N. Francis, 1995: Improved measurements of the ice water content in cirrus using a total-water probe. J. Atmos. Oceanic Technol., 12, 410-414.

Cao, Q., M. Yeary, and G. Zhang, 2012: Efficient ways to learn weather radar polarimetry. IEEE Trans. Educ., 55, 58-68.

Chapon, B., G. Delrieu, M. Gosset, and B. Boudevillain, 2008: Variability of rain drop size distribution and its effect on the $Z-R$ relationship: A case study for intense Mediterranean rainfall. Atmos. Res., 87, 52-65.

Dee, D. P., and Coauthors, 2011: The ERA-Interim reanalysis: Configuration and performance of the data assimilation system. Quart. J. Roy. Meteor. Soc., 137, 553-597.

Delrieu, G., and Coauthors, 2005: The catastrophic flash-flood event of 8-9 September 2002 in the Gard region, France: A first case study for the Cévennes-Vivarais Mediterranean Hydrometeorological Observatory. J. Hydrometeor., 6, 34-52.

— , B. Boudevillain, J. Nicol, B. Chapon, P. E. Kirstetter, H. Andrieu, and D. Faure, 2009: Bollène 2002 experiment: Radar rainfall estimation in the Cevennes-Vivarais region. J. Appl. Meteor. Climatol., 48, 1422-1447.

Doviak, R. J., and D. S. Zrnic, 1993: Doppler Radar and Weather Observations. Academic Press, 458 pp.

Fabry, F., and I. Zawadzki, 1995: Long-term radar observations of the melting layer of precipitation and their interpretation. J. Atmos. Sci., 52, 838-851.

, and W. Szyrmer, 1999: Modeling of the melting layer. Part II: Electromagnetic. J. Atmos. Sci., 56, 3593-3600.

Field, P. R., R. J. Hogan, P. R. A. Brown, A. J. Illingworth, T. W. Choularton, and R. J. Cotton, 2005: Parametrization of iceparticle size distributions for mid-latitude stratiform cloud. Quart. J. Roy. Meteor. Soc., 131, 1997-2017. 
_ A. J. Heymsfield, and A. Bansemer, 2007: Snow size distribution parameterization for midlatitude and tropical ice clouds. J. Atmos. Sci., 64, 4346-4365.

Gelb, A., 1974: Applied Optimal Estimation. MIT Press, 382 pp.

Germann, U., and J. Joss, 2002: Mesobeta profiles to extrapolate radar precipitation measurements above the Alps to the ground level. J. Appl. Meteor., 41, 542-557.

Hardaker, P. J., A. R. Holt, and C. G. Collier, 1995: A melting-layer model and its use in correcting for the bright band in singlepolarization radar echoes. Quart. J. Roy. Meteor. Soc., 121, 495-525.

Heymsfield, A. J., 2003: Properties of tropical and midlatitude ice cloud particle ensembles. Part I: Median mass diameters and terminal velocities. J. Atmos. Sci., 60, 2573-2591.

— A. Bansemer, P. R. Field, S. L. Durden, J. L. Stith, J. E. Dye, W. Hall, and C. A. Grainger, 2002: Observations and parameterizations of particle size distributions in deep tropical cirrus and stratiform precipitating clouds: Results from in situ observations in TRMM field campaigns. J. Atmos. Sci., 59, 3457-3491.

,-- , and C. H. Twohy, 2007: Refinements to ice particle mass dimensional and terminal velocity relationships for ice clouds. Part I: Temperature dependence. J. Atmos. Sci., 64, 1047-1067.

Heyraud, C., W. Szyrmer, S. Laroche, and I. Zawadzki, 2008: Modeling of the melting layer. Part IV: Brightband bulk parameterization. J. Atmos. Sci., 65, 1991-2001.

Kirstetter, P. E., H. Andrieu, G. Delrieu, and B. Boudevillain, 2010: Identification of vertical profiles of reflectivity for correction of volumetric radar data using rainfall classification. J. Appl. Meteor. Climatol., 49, 2167-2180.

, B. Boudevillain and G. Delrieu, 2012: Toward a physicallybased identification of vertical profiles of reflectivity from volume scan radar data. Proc. Int. Symp. on Weather Radar and Hydrology, Exeter, United Kingdom, IAHS Publication 351, 194-200.

Kitchen, M., R. Brown, and A. G. Davies, 1994: Real-time correction of weather radar data for the effects of bright band, range and orographic growth in widespread precipitation. Quart. J. Roy. Meteor. Soc., 120, 1231-1254.

Klaassen, W., 1988: Radar observations and simulation of the melting layer of precipitation. J. Atmos. Sci., 45, 3741-3752.

Matrosov, S. Y., K. A. Clark, and D. E. Kingsmill, 2007: A polarimetric radar to identify rain, melting-layer and snow regions for applying corrections to vertical profiles of reflectivity. J. Appl. Meteor., 46, 154-166.

Mitchell, D. L., R. Zhang, and R. L. Pitter, 1990: Mass-dimensional relationships for ice particles and the influence of riming on snowfall rates. J. Appl. Meteor., 29, 153-163.

Mitra, S. K., O. Vohl, M. Ahr, and H. R. Pruppacher, 1990: A wind tunnel and theoretical study of the melting behavior of atmospheric ice particles. Part IV: Experiment and theory for snowflakes. J. Atmos. Sci., 47, 584-591.

Porrà, J. M., D. Sempere-Torres, and J. D. Creutin, 1998: Modeling of drop size distribution and its applications to rainfall measurements from radar. Stochastic Methods in Hydrology: Rain, Landforms, and Floods, V. K. Gupta et al., Eds., World Scientific, 73-84.

Pruppacher, H., and J. Klett, 1998: Microphysics of Clouds and Precipitation. D. Reidel, 976 pp.

Rasmussen, R. M., and A. J. Heymsfield, 1987: Melting and shedding of graupel and hail. Part I: Model physics. J. Atmos. Sci., 44, 2754-2763.

Rogers, R. R., and M. K. Yau, 1989: A Short Course in Cloud Physics. Pergamon Press, 293 pp.
Ryzhkov, A. V., S. M. Ganson, A. Khain, M. Pinksy, and A. Pokrovsky, 2009: Polarimetric characteristics of melting hail at $\mathrm{S}$ and $\mathrm{C}$ bands. Extended Abstracts, 34th Conf. on Radar Meteorology, Williamsburg, VA, Amer. Meteor. Soc., 4A.6. [Available online at http://ams.confex.com/ams/34Radar/ techprogram/paper_155571.htm.]

—, M. Pinksy, A. Pokrovsky, and A. Khain, 2011: Polarimetric radar observations operator for a cloud model with spectral microphysics. J. Appl. Meteor. Climatol., 50, 873-894.

Sanchez-Diezma, R., I. Zawadzki, and D. Sempere-Torres, 2000: Identification of the bright band through the analysis of volumetric radar data. J. Geophys. Res., 105 (D2), 2225-2236.

Sekhon, R. S., and R. C. Srivastava, 1971: Doppler radar observations of drop-size distributions in a thunderstorm. J. Atmos. Sci., 28, 983-994.

Sempere-Torres, D., J. Porrà, and J.-D. Creutin, 1994: A general formulation for raindrop size distribution. J. Appl. Meteor., 33, 1494-1502.

,$- \ldots$, and $—$, 1998: Experimental evidence of a general description of raindrop size distribution properties. J. Geophys. Res., 103 (D2), 1785-1797.

Seo, D. J., J. P. Breidenbach, R. A. Fulton, D. A. Miller, and T. O'Bannon, 2000: Real-time adjustment of range-dependent bias in WSR-88D rainfall data due to nonuniform vertical profile of reflectivity. J. Hydrometeor., 1, 222-240.

Steiner, M., R. A. Houze Jr., and S. E. Yuter, 1995: Climatological characterization of three-dimensional storm structure from operational radar and rain gauge data. J. Appl. Meteor., 34, 1978-2007.

Szyrmer, W., and I. Zawadzki, 1999: Modeling of the melting layer. Part I: Dynamics and microphysics. J. Atmos. Sci., 56, 3573-3592.

Tabary, P., 2007: The new French operational radar rainfall product. Part I: Methodology. Wea. Forecasting, 22, 393-408.

Testud, J., S. Oury, R. Black, P. Amayenc, and X. Dou, 2001: The concept of normalized distribution to describe raindrop spectra: A tool for cloud physics and cloud remote sensing. J. Appl. Meteor., 40,1118-1140.

Uijlenhoet, R., 1999: Parameterization of rainfall microstructure for radar meteorology and hydrology. Thèse de doctorat, Wageningen University, Netherlands, 279 pp.

, 2001: Raindrop size distributions and radar reflectivity-rain rate relationships for radar hydrology. Hydrol. Earth Syst. Sci., 5, 615-627.

- J. A. Smith, and M. Steiner, 2003a: The microphysical structure of extreme precipitation as inferred from groundbased raindrop spectra. J. Atmos. Sci., 60, 1220-1238.

_ - M. Steiner, and J. A. Smith, 2003b: Variability or raindrop size distribution in a squall line and implication for radar rainfall estimation. J. Hydrometeor., 4, 43-61.

Vignal, B., H. Andrieu, and J. D. Creutin, 1999: Identification of vertical profiles of reflectivity from voluminal radar data. J. Appl. Meteor., 38, 1214-1228.

Westbrook, C. D., R. C. Ball, P. R. Field, and A. J. Heymsfield, 2004: Universality in snowflake aggregation. Geophys. Res. Lett., 31, L15104, doi:10.1029/2004GL020363.

Willis, T. W., and A. J. Heymsfield, 1989: Structure of the melting layer in mesoscale convective system stratiform precipitation. J. Atmos. Sci., 46, 2008-2025.

Zawadzki, I., W. Szyrmer, C. Bell, and F. Fabry, 2005: Modeling of the melting layer. Part III: The density effect. J. Atmos. Sci., 62, 3705-3723. 